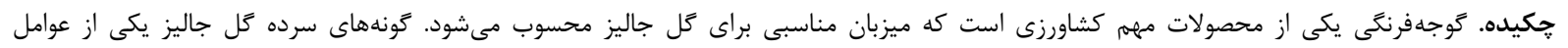

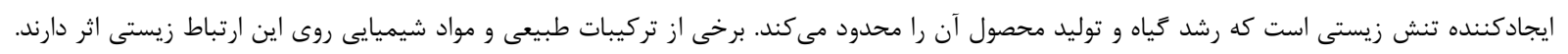

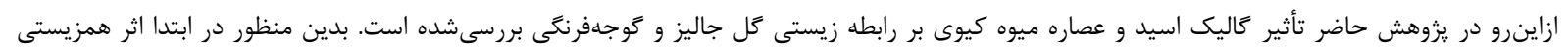

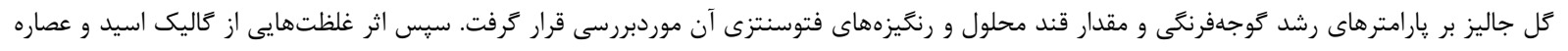

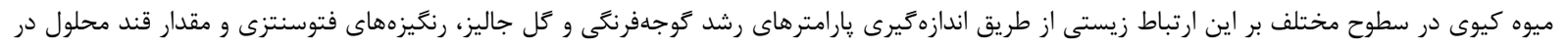

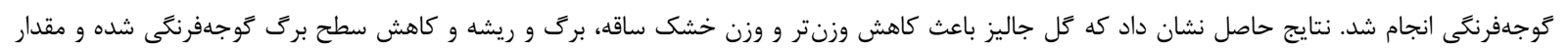

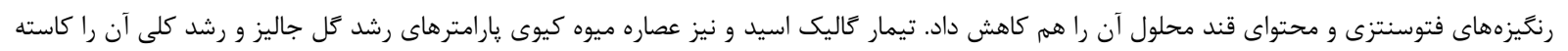

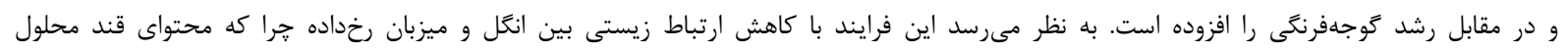

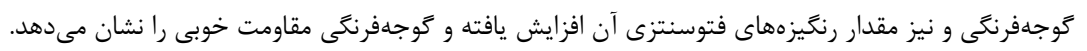
وازههاى كليدى. ارتباط زيستى انتل و ميزبان، آنزيم يكتين متيل استراز، رشد، رنكَيزهاى فتوسنتزى، قند محلول

\title{
The effects of kiwi fruit extract and gallic acid on symbiotic relationship between broomrape and tomato
}

\author{
Azam Salimi, Asrin Arshi \& Maryam Chavoushi \\ Department of Plant Sciences, Faculty of Biological Sciences, Kharazmi University, Tehran, Iran \\ Corresponding Author: Azam salami, salimi@khu.ac.ir
}

\begin{abstract}
Tomato (Solanum lycopersicum) is one of the most important crops and a known host of broomrapes. The species of genus Orobanche are biotic stress factors restricting plant growth and crop production. Some natural compounds and chemicals affect this biological relationship. Therefore, in the present study, the effect of gallic acid and kiwi fruit extract on the biological relationship between broomrape and tomato plant was investigated. To this end, first, the symbiotic effect of the broomrape species, Orobanche aegytica, on growth parameters of tomato plant and the amount of soluble sugar and photosynthetic pigments were evaluated. Then, the effect of concentrations of gallic acid and kiwi fruit extract at different levels on this biological relationship was investigated by measuring the growth parameters of tomato and broomrape, photosynthetic pigments and the amount of soluble sugar in tomatoes. The results demonstrated that the broomrapes reduced the fresh weight and dry weight of the stem, leaves and roots of tomato, diminished the leaf area of the host plant, and decreased the amount of photosynthetic pigments and its soluble sugar content. Gallic acid treatment and kiwi fruit extract lessened the growth parameters of the broomrape species and its overall growth, in addition to increasing the growth of tomato plants. This process could be associated with the constraint of the biological relationship between the parasite and the host, as the soluble sugar content as well as the amount of the photosynthetic pigments of tomato plants were increased and the tomato plants remained highly resistant.
\end{abstract}

Key words. growth, parasite, pectin methylesterase, photosynthetic pigments, solute sugar 
زندگى گل جاليز را در برمى گيرند؛ اما هنوز استراتزى قطعى و مؤثرى معرفى نشده است؛ بنابراين، لازم است با توجه بـ بهن

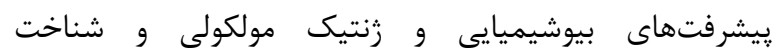

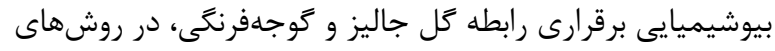

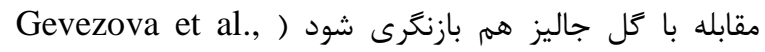

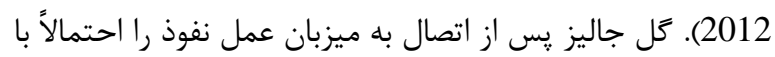

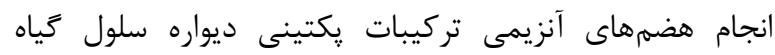

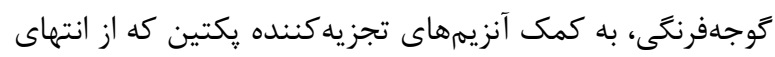

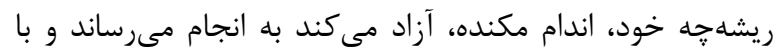

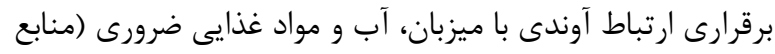

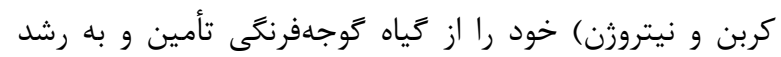
خود ادامه مىدهد (Fernández-Aparicio et al., 2020)،

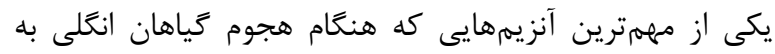

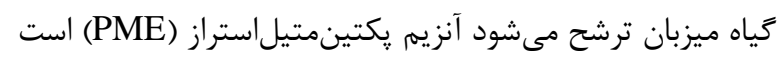

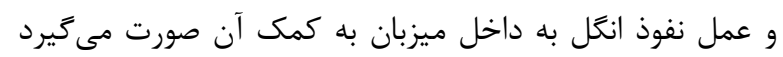

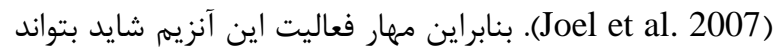

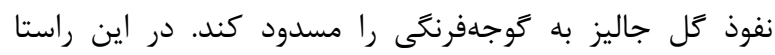

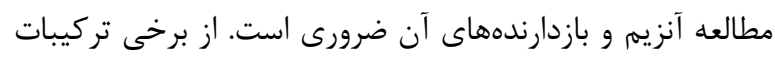

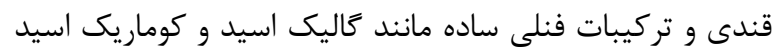

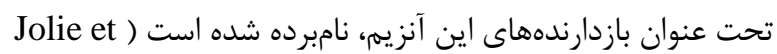

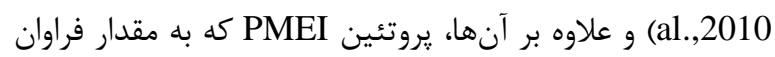

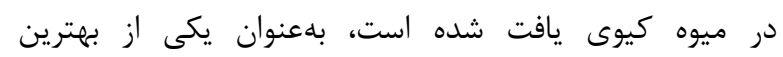

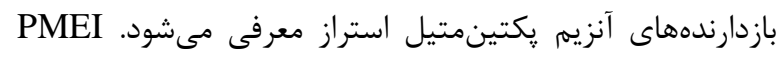

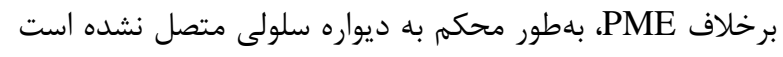

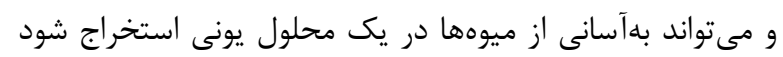
(Jolie et al., 2010)

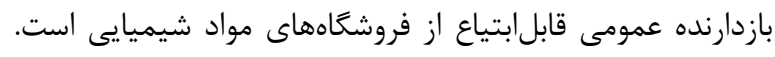

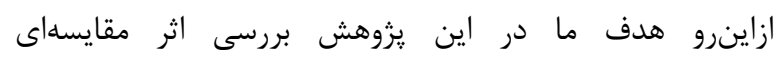

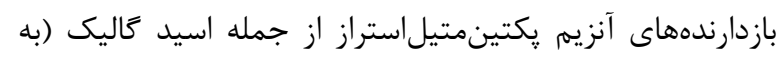

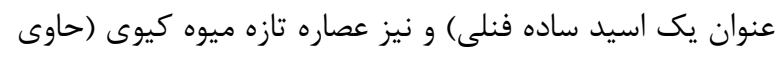

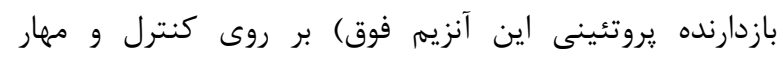

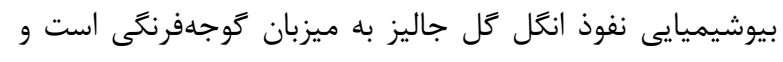

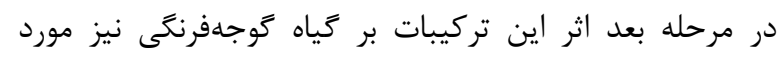
بر برى قرار خواهد ترفت.

$$
\text { مواد و روشها }
$$

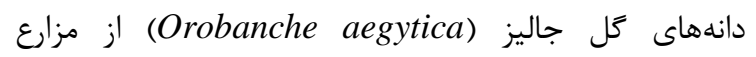
كوجه فرنكى آلوده به كل جاليز در روستاى كوسه كهريزه از توابع

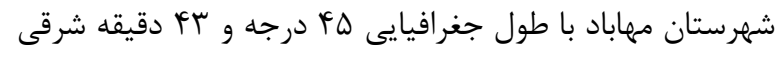

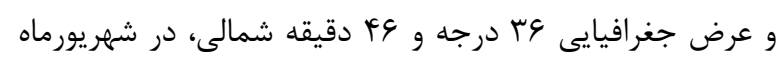

مقدمه - مقه

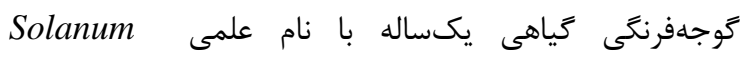
lycopersicum L.

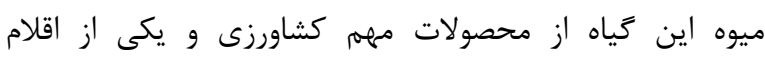

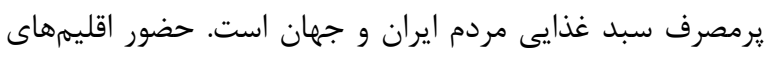

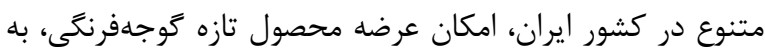

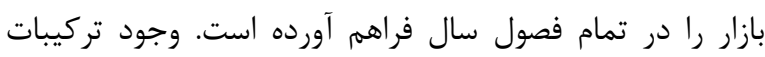

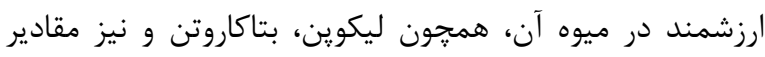

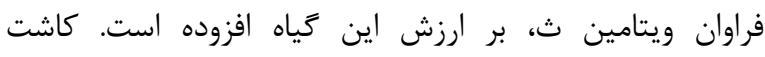

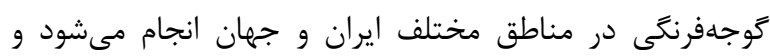

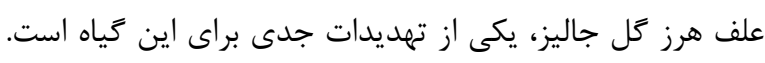

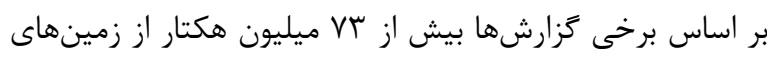

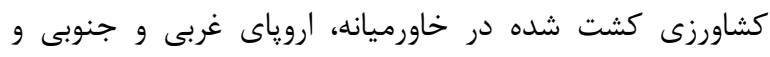

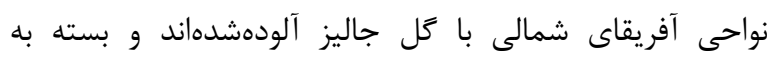

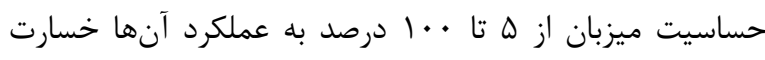

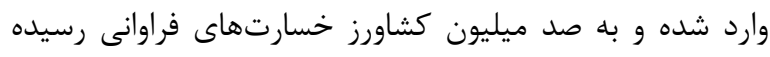

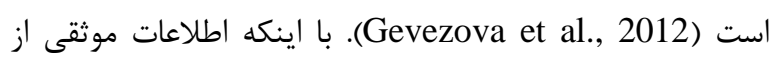

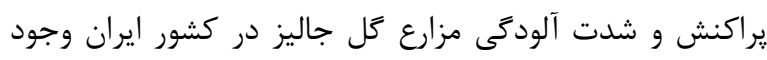
ندارد (Torabi \& Hadizadeh, 2014) اما همواره كشاورزان بسيارى، از اين آلودگى دجار خسارت شدهاند. بنابراين مديريت،

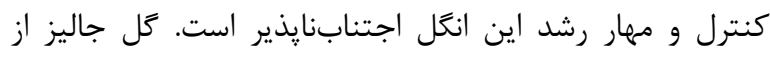

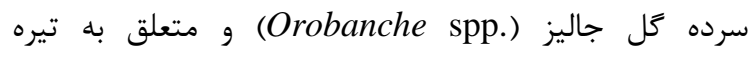
Orobancaceae

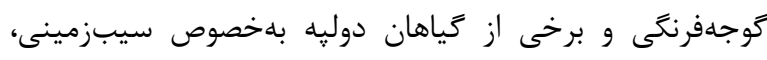

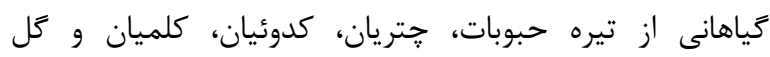
ستارهاىها است (Eizenberg \& Goldwasser, 2018). كل جل جاليز به دليل نداشتن كلروفيل، با جذب آب آب و مواد غذايى از إناء

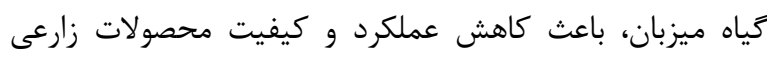

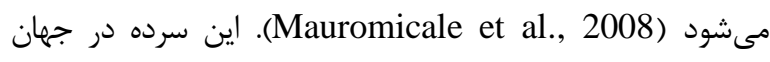

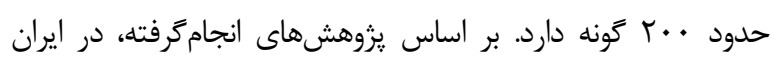

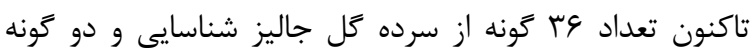
Orobanche cernua Loefl. و Orobanche aegeptica Pers. Torabi \& ) در فهرست مهمترين علفهاى هرز انكل معرفى شدهاند (Hadizadeh, 2014; Karampour, 2010 كنترل گل جاليز بسيار مشكل است زيرا با ميزبان ارتباط

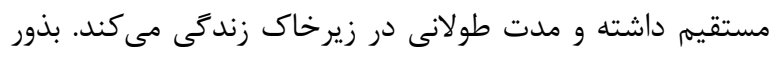

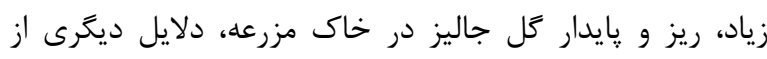

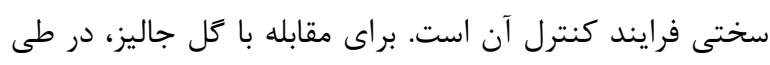

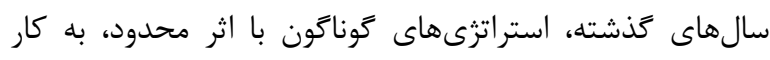
كرفتهشده است. استراتزىهايى كه مراحل خاصى ازئه إن خرخه 
به داخل گياه • r روز يس از كاشت نشاء در خاكآلوده به انكل

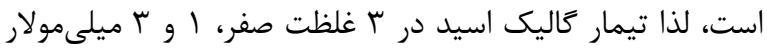
(Sasikumar et al., 2006)

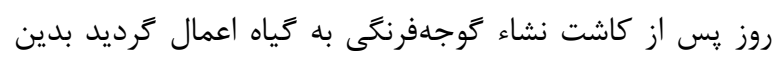
صورت كه مقدارى از خاك اطراف نشاء را كنار كذاشته و و تيمارها

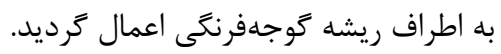

تيمار عصاره ميوه كيوى

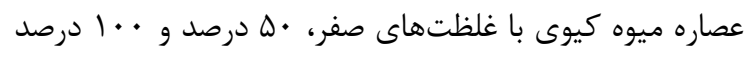

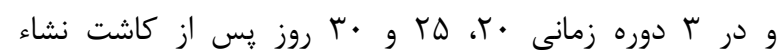

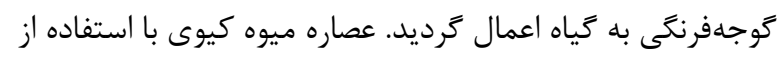

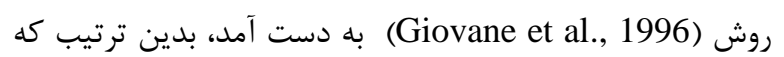

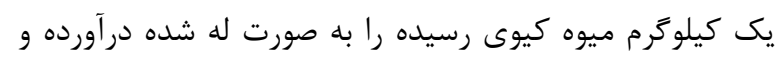

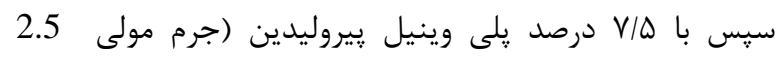

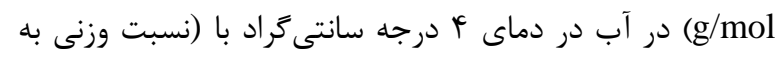

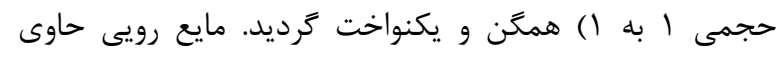

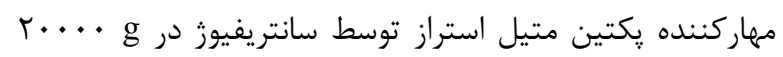

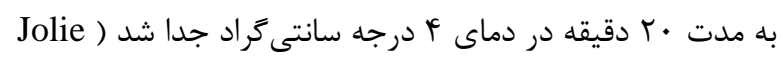
et al., 2009

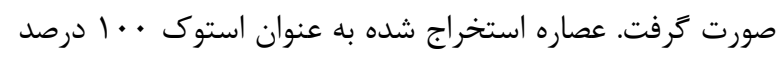

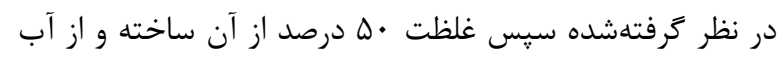

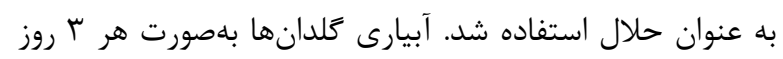
يكبار انجام شد.

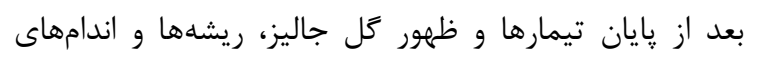

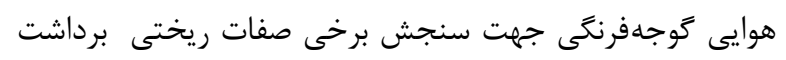

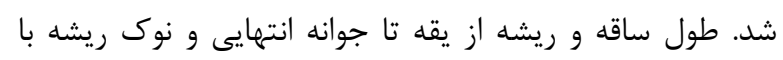

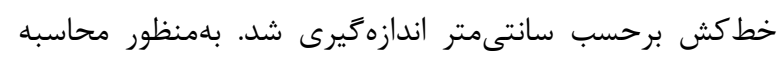

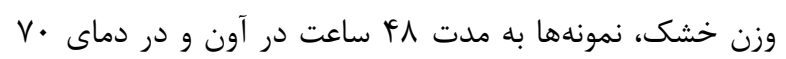

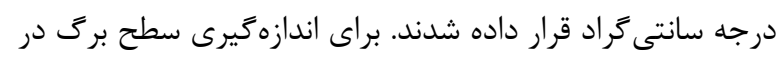

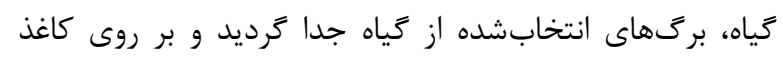
شطرنجى قرار داده و سطح برى محاسبه كرديد. سنجش كلروفيلها

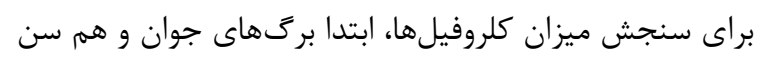

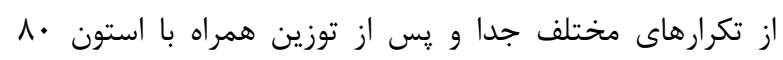

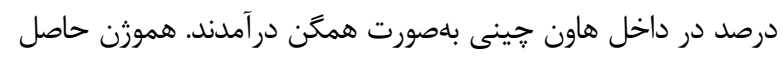

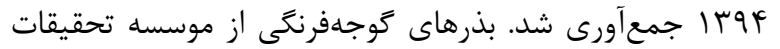

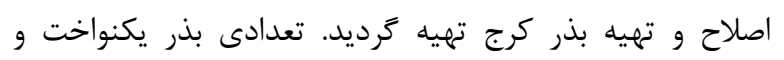

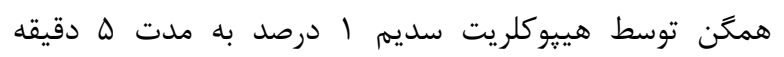

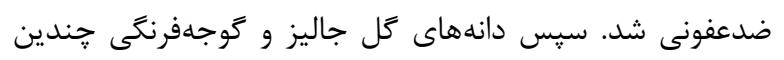

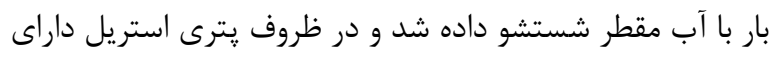

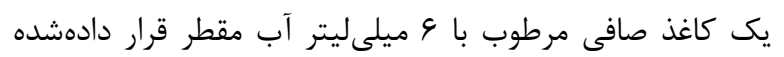

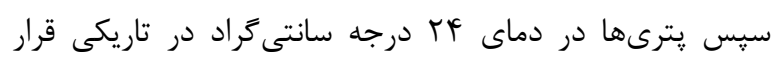

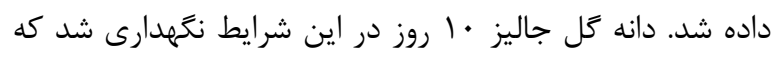

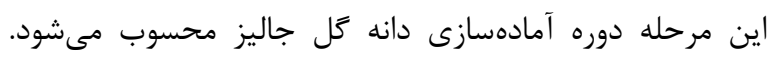

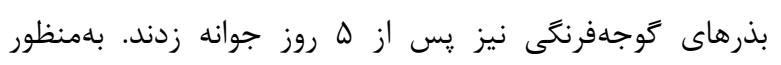

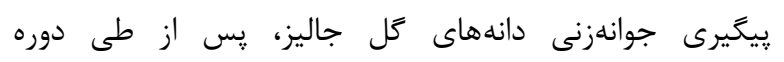

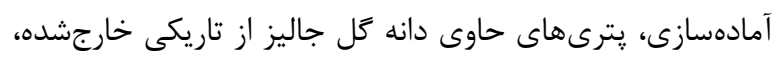

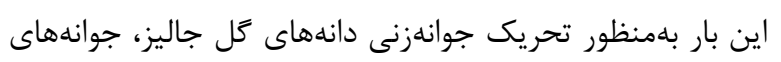

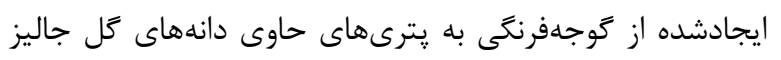

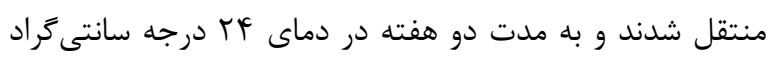

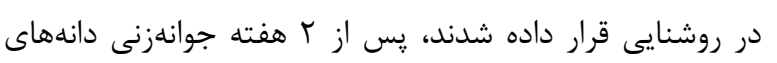

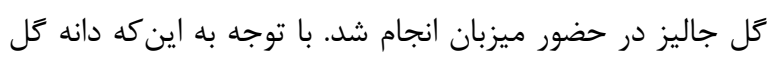

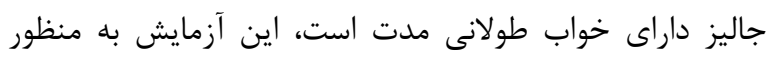

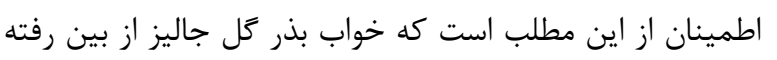

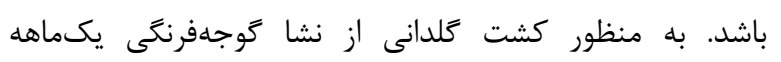

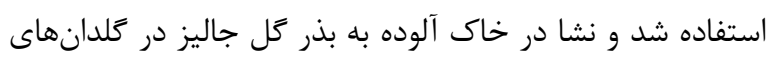

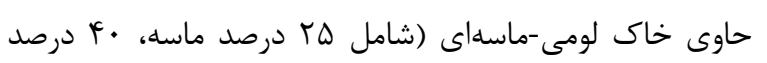

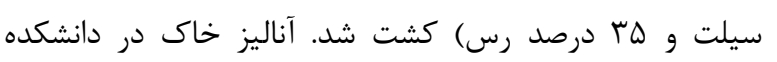
كشاورزى دانشعاه تهران بخش خاكشناسى درص انجام شد كد كه نتايج

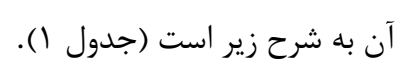

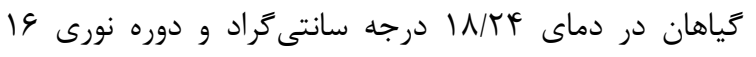

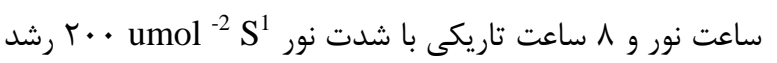

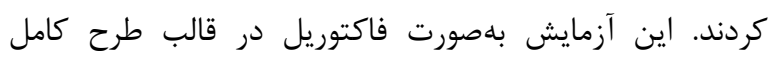

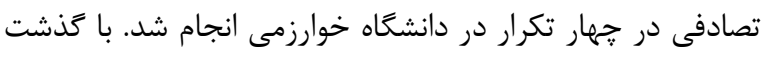

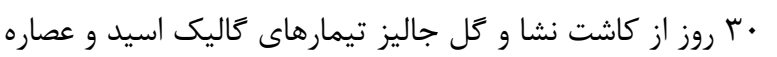
ميوه كيوى به شرح زير اعمال شد. تيمار كاليك اسيد

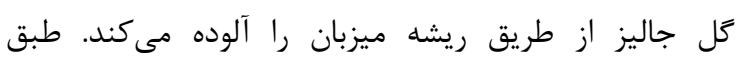
يزوهشهاى ييشين حداقل زمان لازم براى جوانهزنى و نفوذ انكل

جدول ا- نتايج آناليزهاى انجامشده بر نمونهاى از خاك مورداستفاده.

Table 1. The results of the analyzes of soil sample.

\begin{tabular}{|c|c|c|c|c|c|c|c|c|c|c|}
\hline كلاس بافت & $\begin{array}{c}\text { Sand } \\
(\%)\end{array}$ & $\begin{array}{c}\text { Silt } \\
(\%)\end{array}$ & $\begin{array}{c}\text { Clay } \\
(\%)\end{array}$ & $\begin{array}{c}\text { OC } \\
(\%)\end{array}$ & $\begin{array}{c}\text { FC } \\
(\%)\end{array}$ & $\begin{array}{c}\text { K } \\
(\mathrm{ppm})\end{array}$ & $\begin{array}{c}\mathrm{P} \\
(\mathrm{ppm})\end{array}$ & $\begin{array}{c}\text { TN } \\
(\%)\end{array}$ & $\begin{array}{c}\mathrm{EC} \\
\left(\mathrm{dsm}^{-1}\right)\end{array}$ & $\mathrm{pH}$ \\
\hline Lo & 25 & 40 & 35 & 0.9 & 51 & 446 & 6.1 & 0.09 & 0.902 & 7.82 \\
\hline
\end{tabular}


نتايج حاصل از تيمار كاليك اسيد بر تعداد كرهك 5 تل جاليز نشان

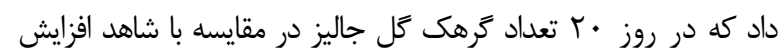

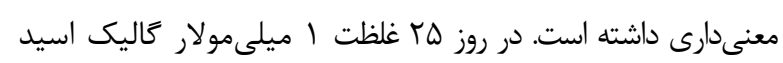

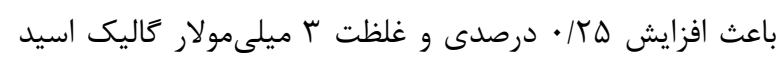

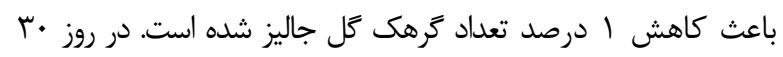

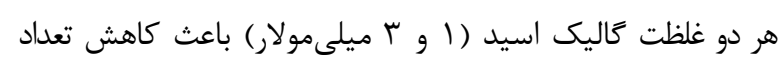

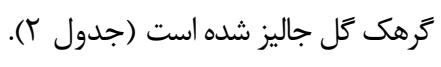

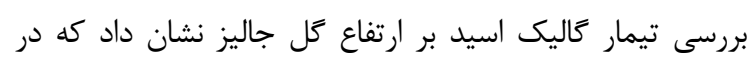

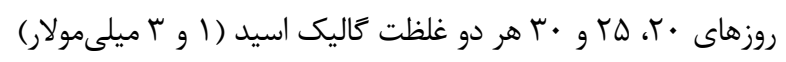

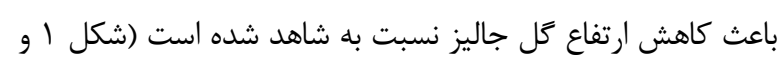

جدول باعث كاهث

بررسى رشد ريشه گل جاليز نشان داد كه كاليك اسيد با غلظت

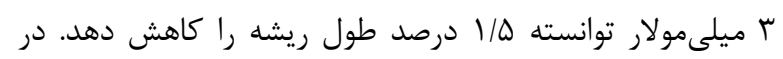

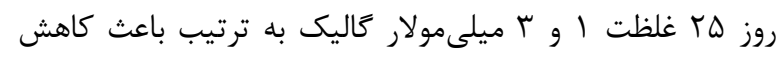

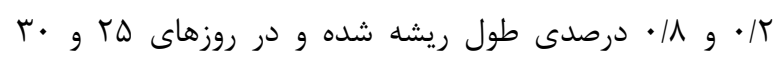

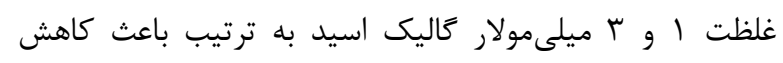

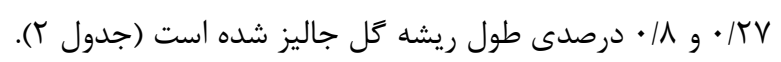

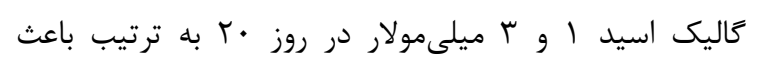

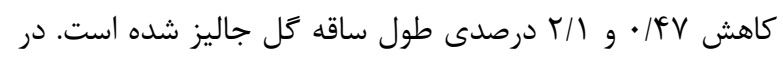

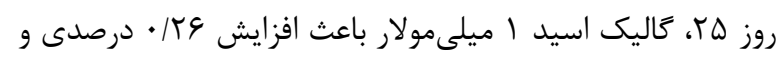

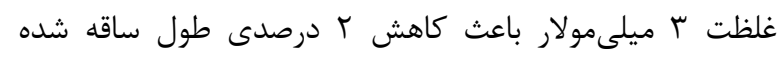

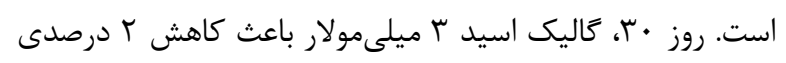

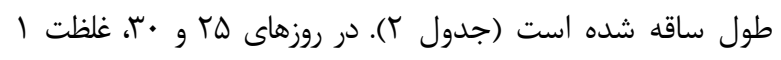

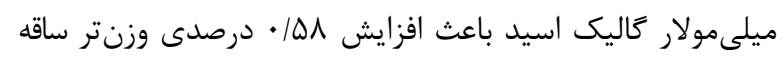

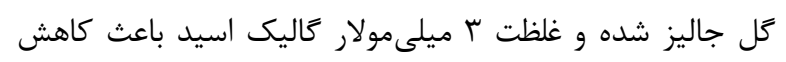

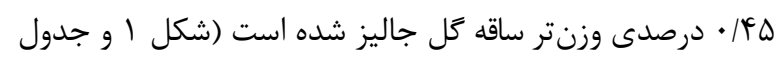

بررسى وزن تر ريشه كل جاليز نشان داد كه در روز • ب كاليك

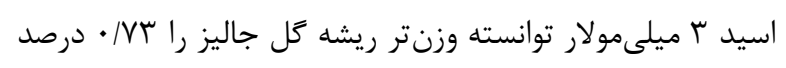

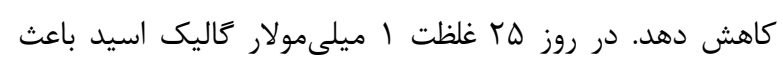

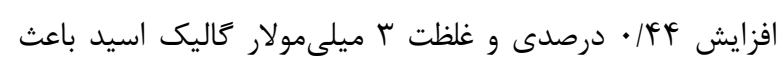

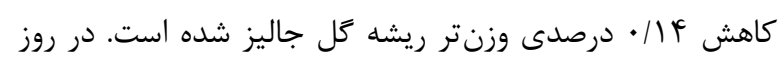

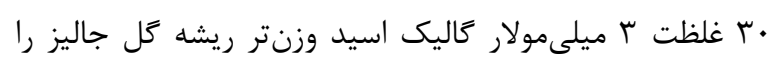

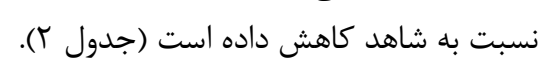

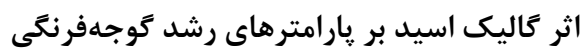

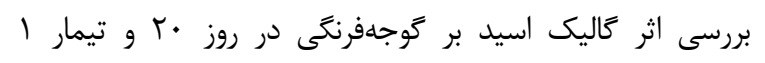

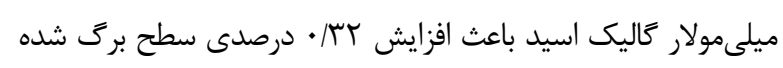

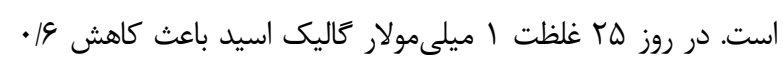

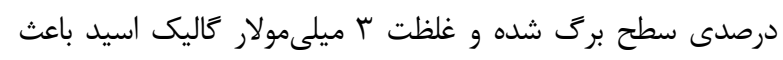

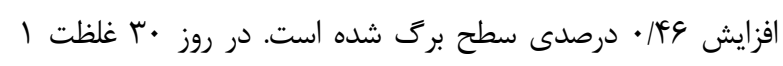

از بركها را از كاغذ صافى واتمن شمارهى r عبور داده و جذب إنا

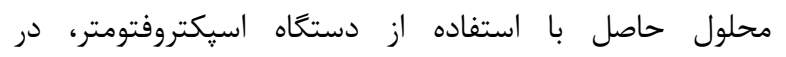

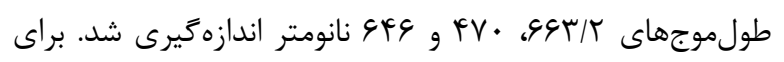

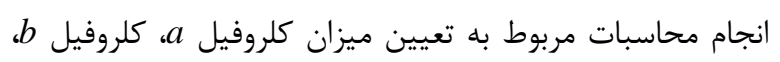

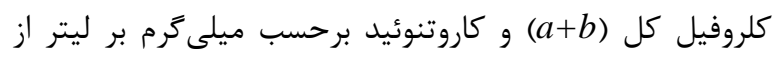

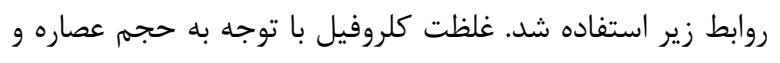

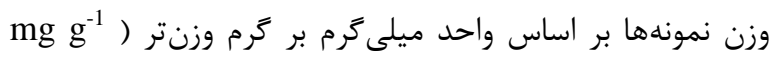

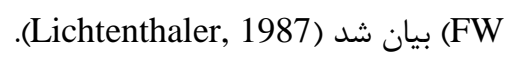

Chl $a\left(\mathrm{mg} \mathrm{ml}^{-1}\right)=12.25 \times \mathrm{A}_{663.2}-2.79 \times \mathrm{A}_{646.8}$

$\mathrm{Chl} b\left(\mathrm{mg} \mathrm{ml}^{-1}\right)=21.51 \times \mathrm{A}_{646.8}-5.1 \times \mathrm{A}_{663.2}$

$\mathrm{Chl}(a+b)=\mathrm{Chl} a+\mathrm{Chl} b$

$\mathrm{C}(\mathrm{x}+\mathrm{c})=\left(1000 \times \mathrm{A}_{470}-1.8 \times \mathrm{Chl} a-85.52 \times \mathrm{Chl} b\right) / 198$

\section{سنجش كربوهيدرات محلول}

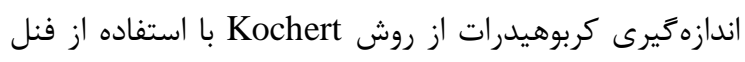

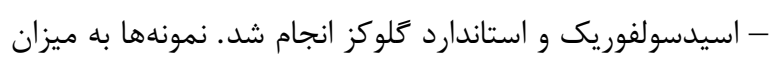

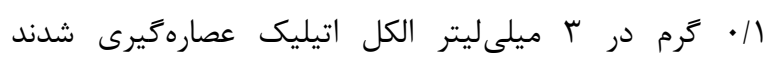

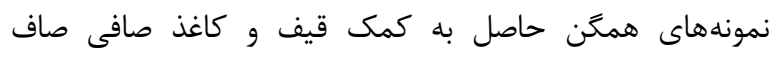

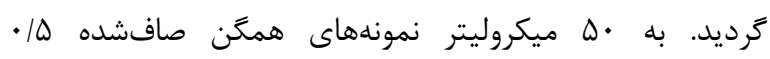

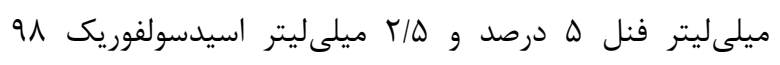

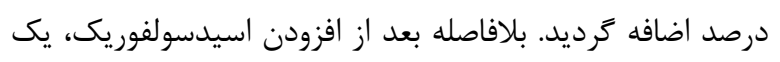

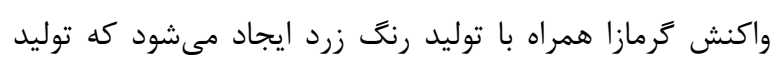

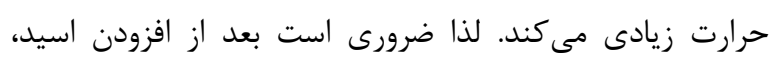

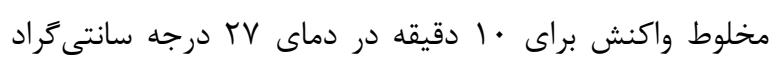

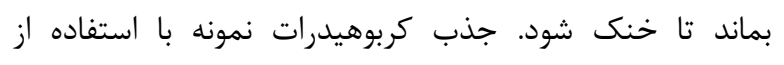

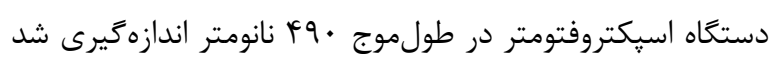

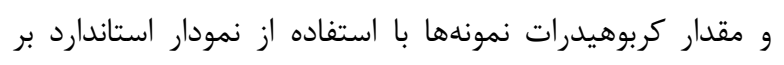

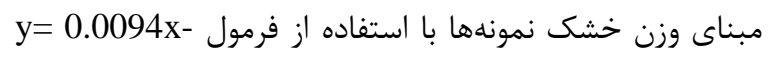
0.0118 محاسبه كرديد (Kochert, 1978)

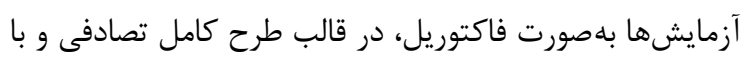

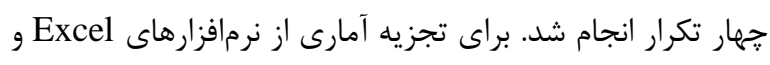

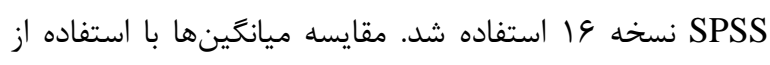
آزمون دانكن در سطح احتمال ه درصد انجام گرديد.

\section{نتايج}

اثر كاليك اسيد بر رشد كل جاليز

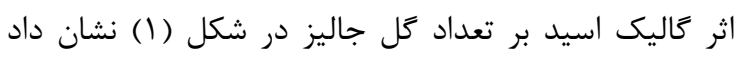

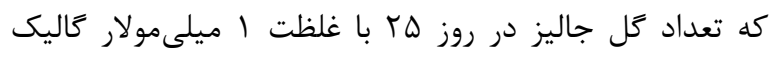

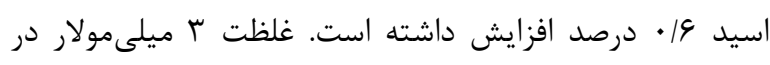

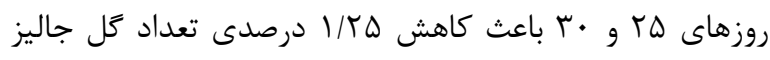

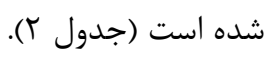


كلروفيل b شده است. در روز ها غلظت ا ميلىمولار گاليك اسيد

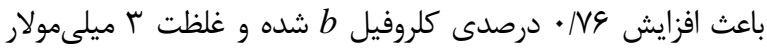

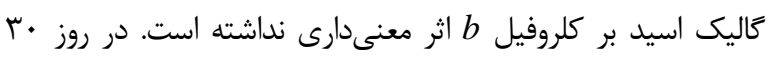

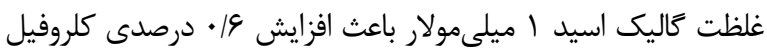

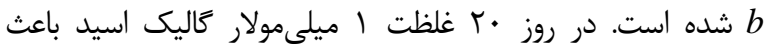

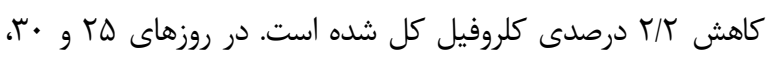

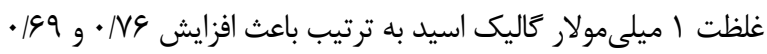

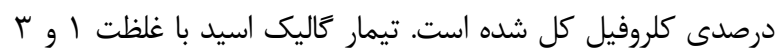

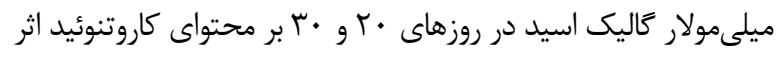

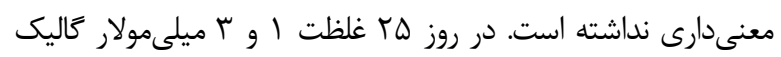

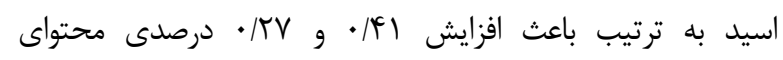

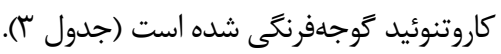

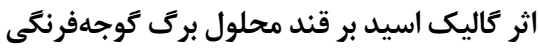

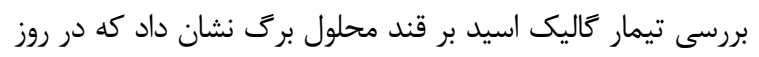

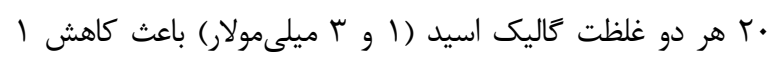

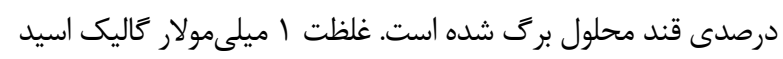

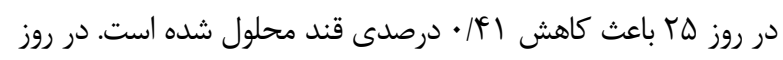

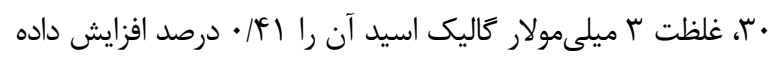

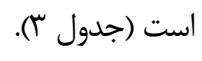

\section{اثر عصاره ميوه كيوى بر رشد كل جاليز}

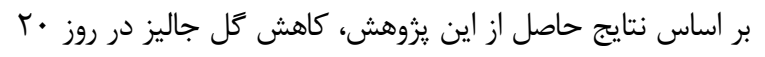

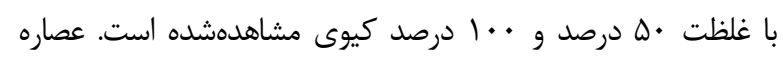

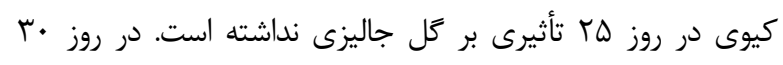

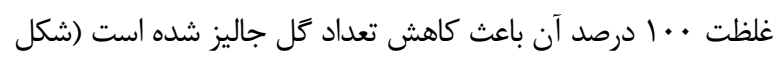

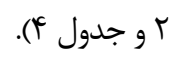

نتايج حاصل از تيمار عصاره ميوه كيوى بر تعداد كرهك گل جل جاليز

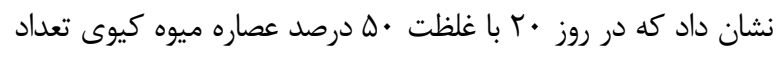

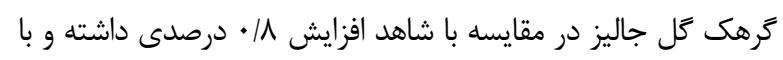

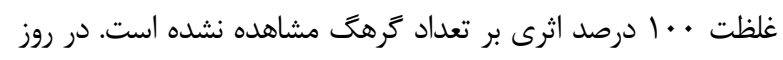

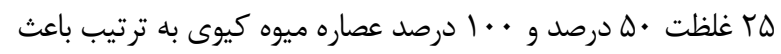

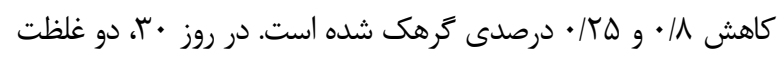

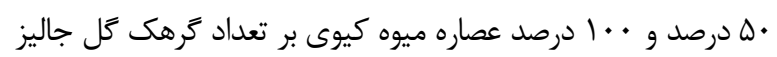

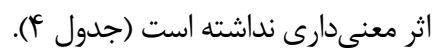

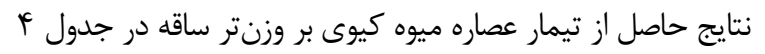

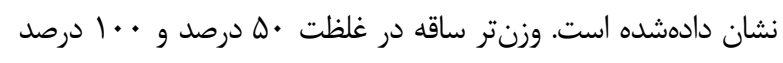

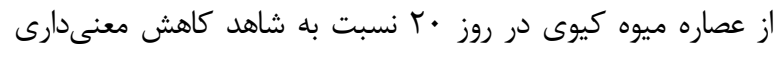

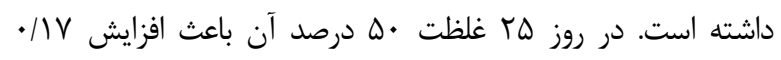

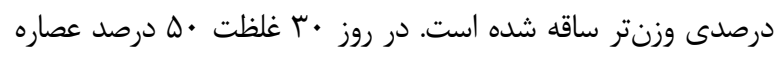

ميلىمولار تاليك اسيد ا درصد سطح برك را كاهش داده و غلظت ؟

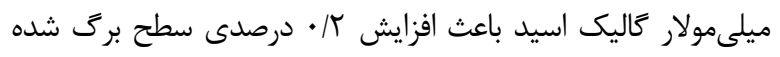

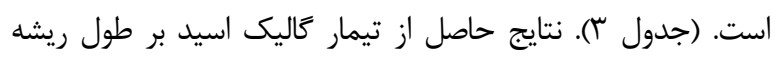

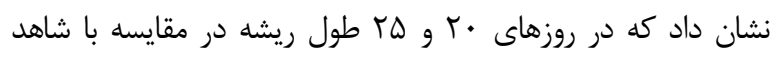

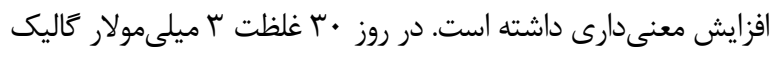

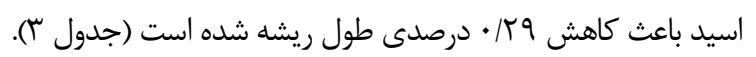

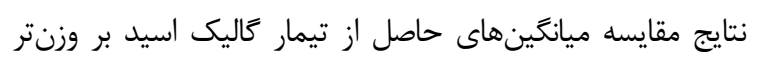

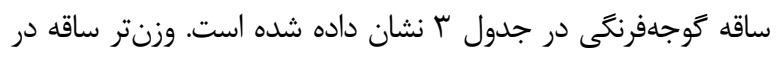

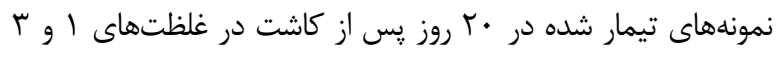

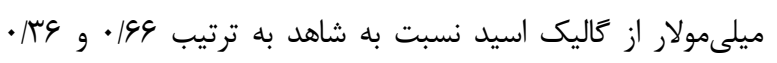

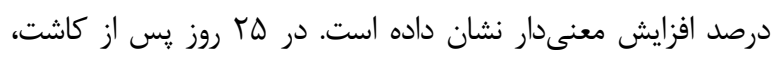

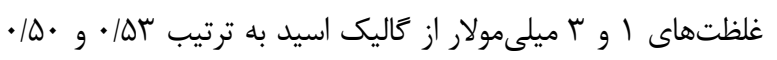

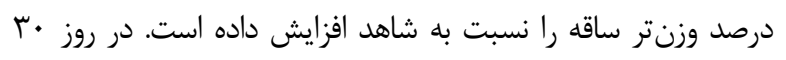

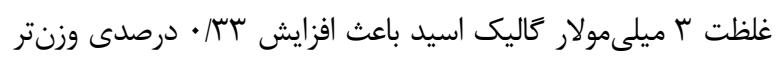

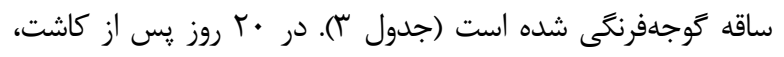

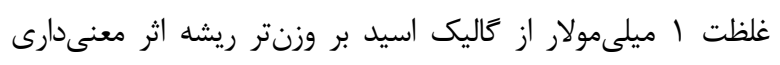

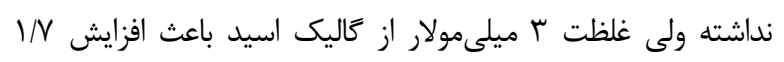

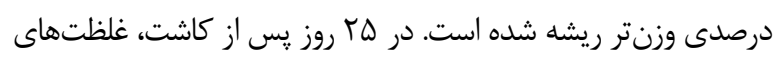

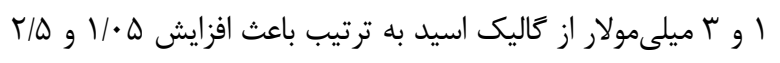

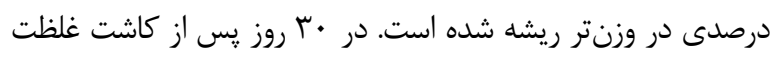

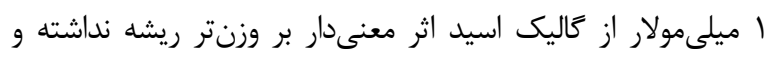

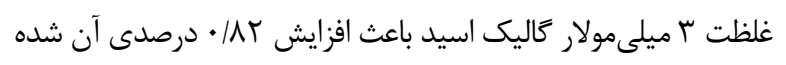
وزن خشك ريشه در غلظت ا و ب ميلىمولار از كاليك اسيد در

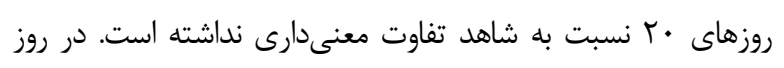

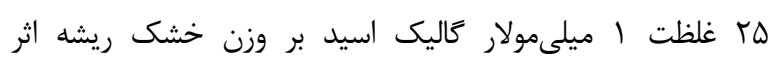

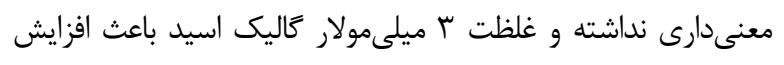

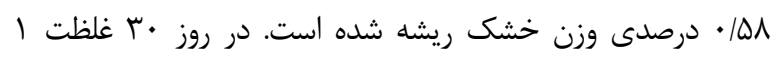

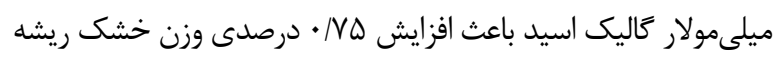

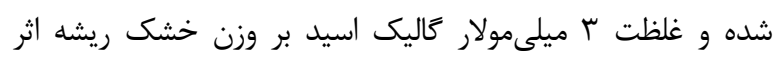

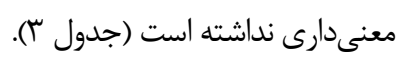

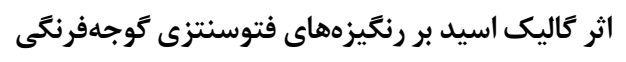

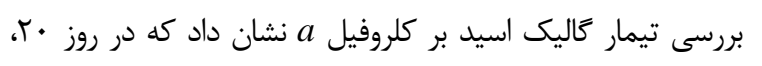

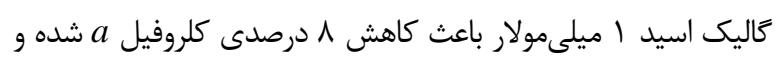

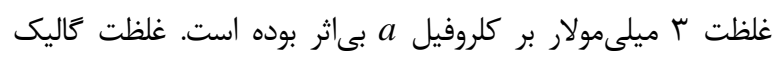

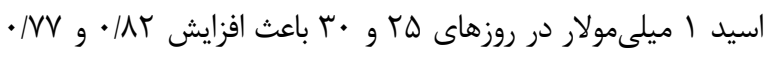

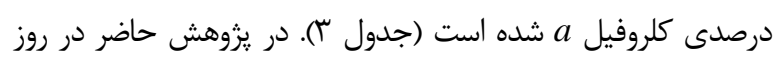

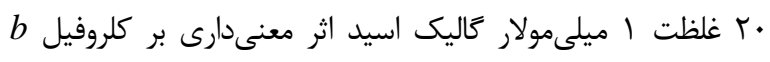

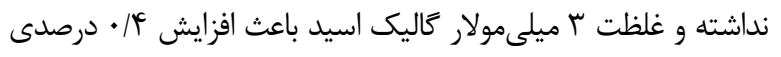




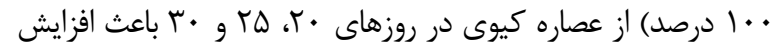

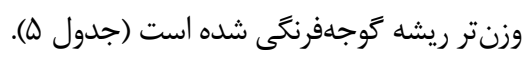

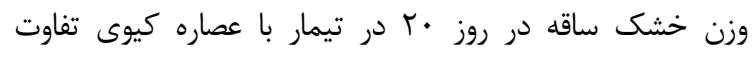

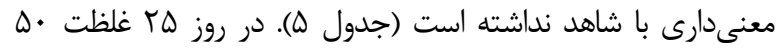

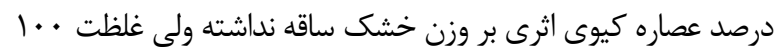

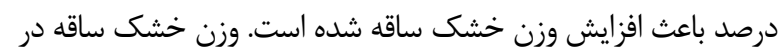

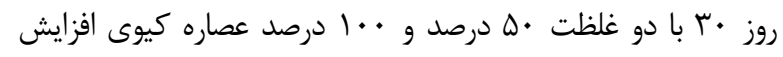

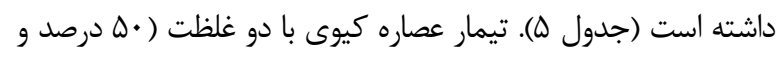

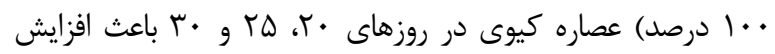

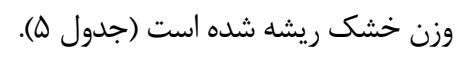

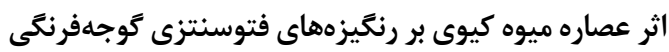

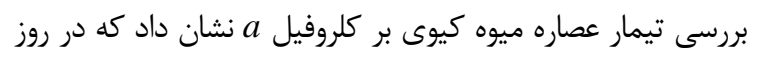

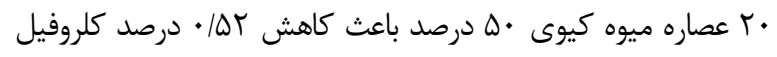

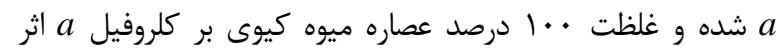

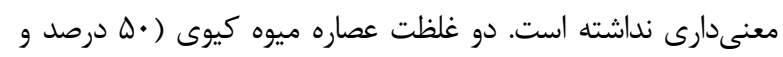

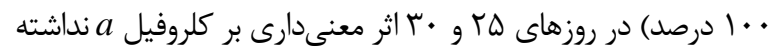

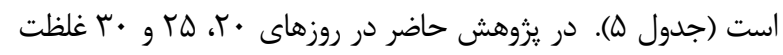

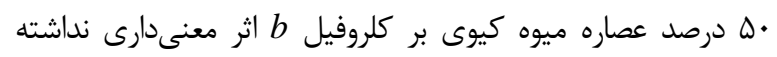

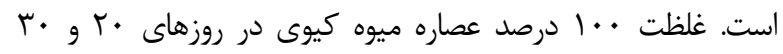

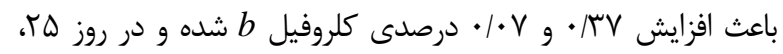

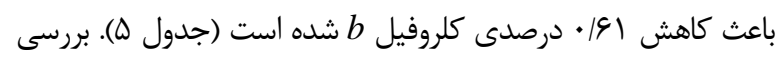

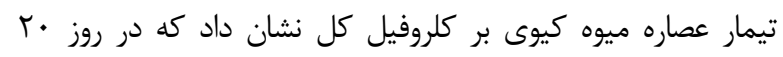

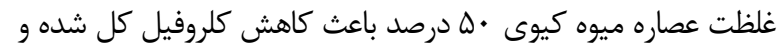

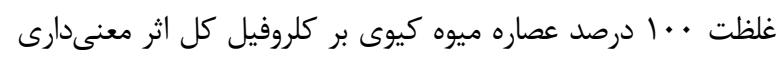

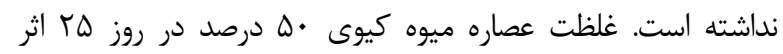

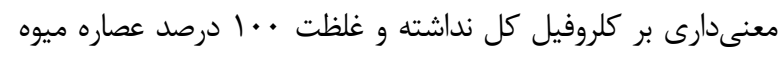

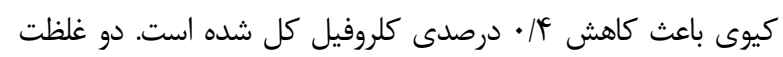

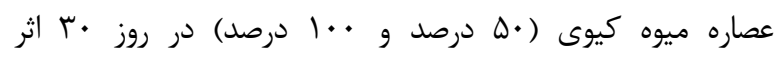

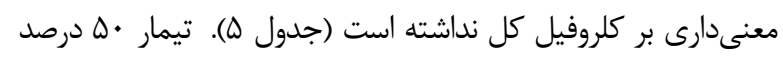

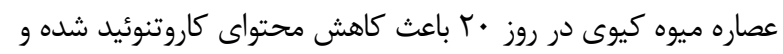

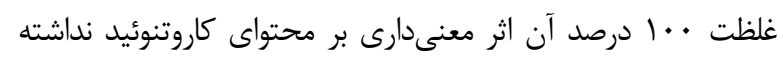

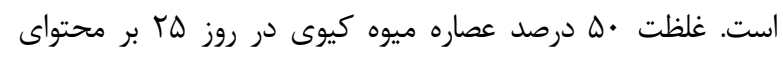

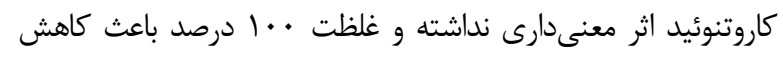

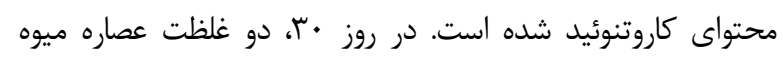
كيوى بر محتواى كاروتنوئيد اثر معنى دارى نداشته است.

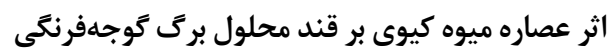

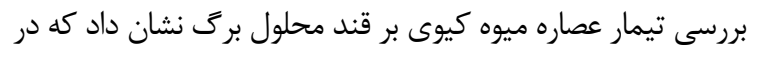

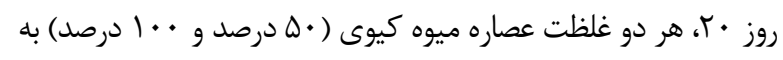

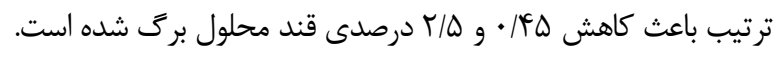

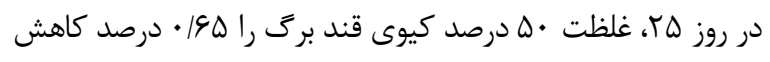

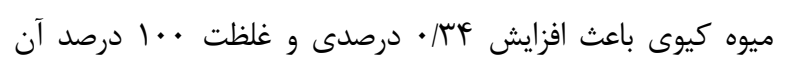
باعث كاهش ص\&\& • • درصدى وزنتر ساقه شده است.

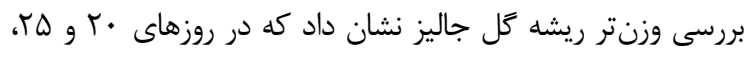

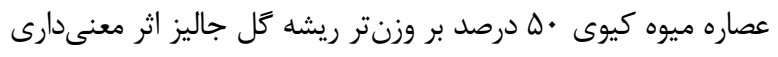

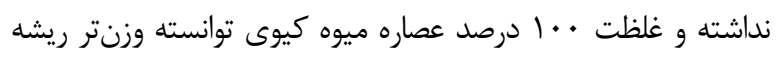

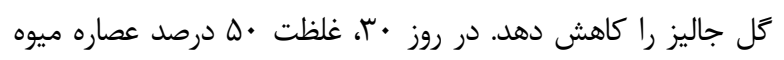

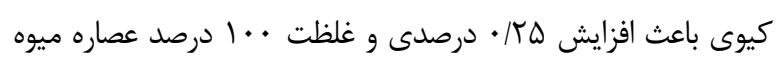

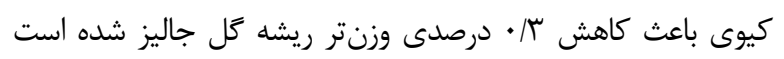

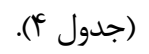
بررسى تيمار عصاره ميوه كيوى بر ارتفاع كل جاليز نشان داد كه در

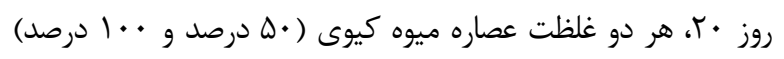

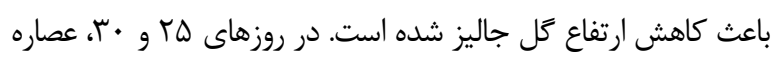

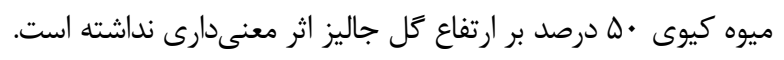

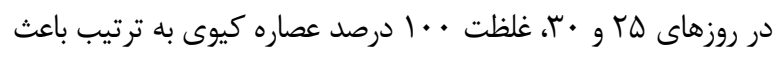

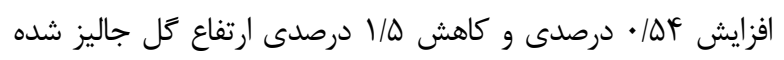
است (شكل r و جدول عأ).

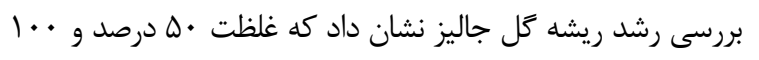

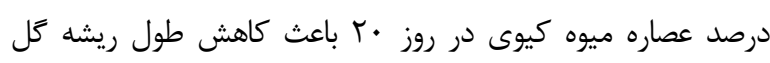

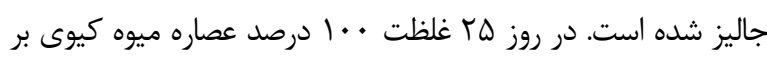

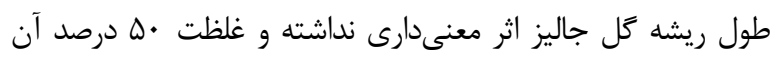

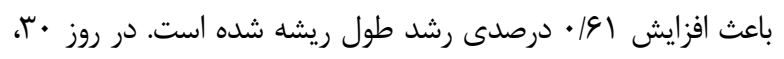

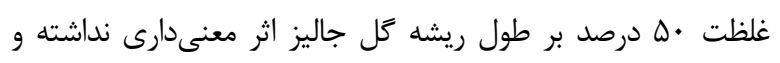

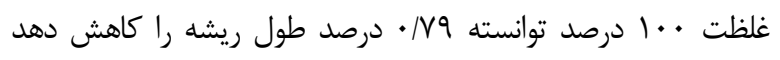

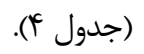

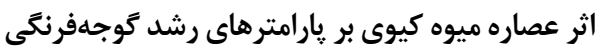

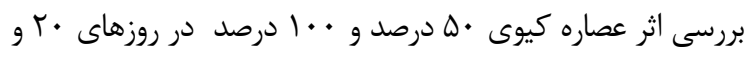

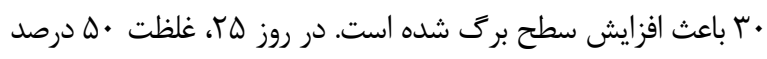

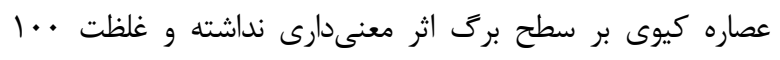

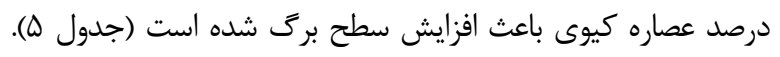

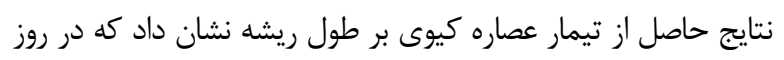

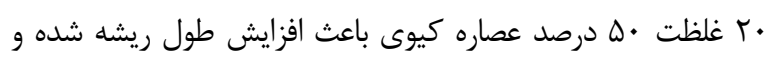

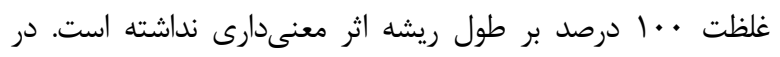

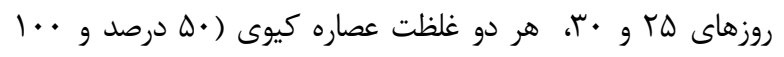

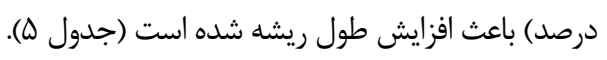

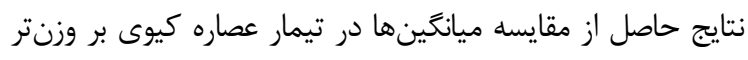

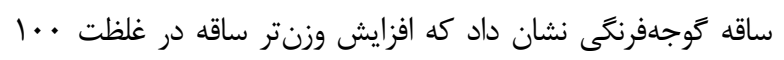

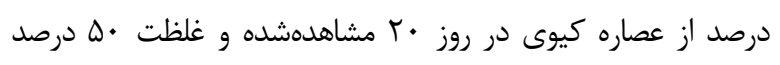

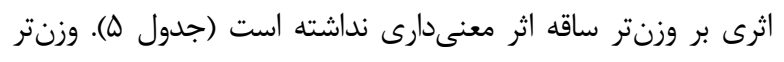

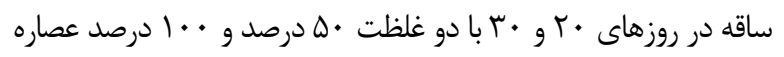

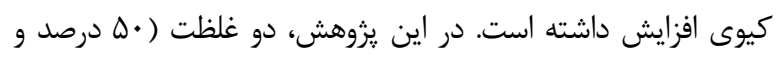




$$
\text { جدول r- اثر كاليك اسيد بر رشد گل جاليز. }
$$

Table 2. Effect of gallic acid on the growth of broomrape.

\begin{tabular}{|c|c|c|c|c|c|c|c|}
\hline زمان (روز) & غلظت كاليخ & تعداد كل جاليز & تعداد كرهك گل جاليز & $\begin{array}{c}\text { وزنتر ساقه } \\
\text { (g) }\end{array}$ & $\begin{array}{c}\text { وزنتر ريشه } \\
\text { (g) }\end{array}$ & $\begin{array}{c}\text { طول ساقه } \\
\text { (cm) }\end{array}$ & $\begin{array}{c}\text { طول ريشه } \\
\text { (cm) }\end{array}$ \\
\hline 20 & 0 & $1.25 \mathrm{~b}$ & $0.25 d$ & $0.62 c$ & $0.53 b$ & $6.25 \mathrm{a}$ & $2.0 \mathrm{ab}$ \\
\hline 20 & 1 & $1.50 \mathrm{~b}$ & $1.50 \mathrm{~b}$ & $0.54 \mathrm{c}$ & $0.49 b$ & $4.25 c$ & $2.3 \mathrm{a}$ \\
\hline 20 & 3 & $1.26 \mathrm{~b}$ & $1.00 \mathrm{c}$ & $0.45 \mathrm{c}$ & $0.14 \mathrm{c}$ & $2.06 \mathrm{~d}$ & $0.8 \mathrm{c}$ \\
\hline 25 & 0 & $1.24 \mathrm{~b}$ & $0.25 \mathrm{~d}$ & $0.62 \mathrm{c}$ & $0.53 b$ & $6.25 \mathrm{a}$ & $2.0 \mathrm{ab}$ \\
\hline 25 & 1 & $3.75 \mathrm{a}$ & $2.00 \mathrm{a}$ & $1.31 \mathrm{a}$ & $0.88 \mathrm{a}$ & $5.75 b$ & $1.9 \mathrm{~b}$ \\
\hline 25 & 3 & $0.00 \mathrm{c}$ & $0.00 \mathrm{e}$ & $0.00 \mathrm{~d}$ & $0.00 \mathrm{c}$ & $0.00 \mathrm{e}$ & $0.0 \mathrm{~d}$ \\
\hline 30 & 0 & $1.25 \mathrm{~b}$ & $0.25 \mathrm{~d}$ & $0.62 \mathrm{c}$ & $0.53 b$ & $6.25 \mathrm{a}$ & $2.0 \mathrm{ab}$ \\
\hline 30 & 1 & $1.25 \mathrm{~b}$ & $0.00 \mathrm{e}$ & $0.95 b$ & $0.51 b$ & $4.25 \mathrm{c}$ & $1.8 \mathrm{~b}$ \\
\hline 30 & 3 & $0.00 \mathrm{c}$ & $0.00 \mathrm{e}$ & $0.00 \mathrm{~d}$ & $0.00 \mathrm{c}$ & $0.00 \mathrm{e}$ & $0.0 \mathrm{~d}$ \\
\hline
\end{tabular}

جدول س- اثر گاليك اسيد بر سطح برك، طول ريشه و وزنتر ساقه و ريشه، وزن خشك ساقه و ريشه، رنخيزهاى فتوسنتزى و قند محلول گوجهفرنگى.

Table 3. Effect of gallic acid on the leaf area, root length and shoot fresh weight, root fresh weight, shoot dry weight and root dry weight, photosynthesis pigments and sugar content of tomato.

\begin{tabular}{|c|c|c|c|c|c|c|c|c|c|c|c|c|}
\hline زمان & $\begin{array}{c}\text { كاليخ } \\
\text { (mM) }\end{array}$ & $\begin{array}{c}\text { سطح } \\
= \\
\left(\mathrm{cm}^{2}\right)\end{array}$ & $\begin{array}{l}\text { ريشه } \\
\text { (cm) }\end{array}$ & ساقه & وزنتر & وزن خشك & وزيشه خشك) & $\begin{array}{c}a \text { كلروفيل } \\
\left(\mathrm{mg} \mathrm{g}^{-1}\right. \\
\mathrm{FW})\end{array}$ & $\begin{array}{c}b \text { كلروفيل } \\
\left(\mathrm{mg} \mathrm{g}^{-1}\right. \\
\mathrm{FW})\end{array}$ & $\begin{array}{c}\text { كلروفيل } \\
\text { كل } \\
\left(\mathrm{mg} \mathrm{g}^{-1}\right. \\
\text { FW) }\end{array}$ & $\begin{array}{c}\text { كاروتنوئيد } \\
\left(\mathrm{mg} \mathrm{g}^{-1}\right. \\
\text { FW) }\end{array}$ & $\begin{array}{c}\text { قند محلول } \\
\left(\mathrm{mg} \mathrm{g}^{-1}\right. \\
\text { FW) }\end{array}$ \\
\hline 20 & 0 & $6.8 \mathrm{~cd}$ & $7.5 \mathrm{~d}$ & $1.06 \mathrm{c}$ & $0.68 \mathrm{~d}$ & $0.13 \mathrm{c}$ & $0.09 \mathrm{~b}$ & $0.119 a b$ & $0.062 \mathrm{~cd}$ & $0.181 \mathrm{~b}$ & $0.059 \mathrm{bc}$ & $4.87 \mathrm{a}$ \\
\hline 20 & 1 & $10.1 \mathrm{~b}$ & $9.7 \mathrm{c}$ & $1.77 \mathrm{a}$ & $0.88 \mathrm{~d}$ & $0.17 b c$ & $0.08 \mathrm{~b}$ & $0.022 \mathrm{c}$ & $0.032 \mathrm{~d}$ & $0.056 \mathrm{c}$ & $0.043 \mathrm{~cd}$ & $2.47 \mathrm{~b}$ \\
\hline 20 & 3 & $8.3 \mathrm{bc}$ & $15.5 \mathrm{a}$ & $1.4 \mathrm{ab}$ & $1.88 \mathrm{~b}$ & $0.20 b c$ & $0.12 b$ & $0.085 \mathrm{~b}$ & $0.106 \mathrm{~b}$ & $0.191 \mathrm{~b}$ & $0.047 \mathrm{~cd}$ & $2.57 \mathrm{~b}$ \\
\hline 25 & 0 & $6.8 \mathrm{~cd}$ & $7.5 \mathrm{~d}$ & $1.06 \mathrm{c}$ & $0.68 \mathrm{~d}$ & $0.13 \mathrm{c}$ & $0.09 \mathrm{~b}$ & $0.119 a b$ & $0.062 \mathrm{~cd}$ & $0.181 \mathrm{~b}$ & $0.05 b c$ & $4.87 \mathrm{a}$ \\
\hline 25 & 1 & $6.0 \mathrm{~d}$ & $13.6 \mathrm{~b}$ & $1.60 \mathrm{a}$ & $1.40 \mathrm{c}$ & $0.13 \mathrm{c}$ & $0.11 \mathrm{~b}$ & $0.128 \mathrm{a}$ & $0.136 \mathrm{a}$ & $0.264 \mathrm{a}$ & $0.074 \mathrm{a}$ & $1.74 \mathrm{c}$ \\
\hline 25 & 3 & $15 \mathrm{a}$ & $13.0 \mathrm{~b}$ & $1.63 \mathrm{a}$ & $2.40 \mathrm{a}$ & $0.22 \mathrm{ab}$ & $0.29 a$ & $0.111 \mathrm{ab}$ & $0.086 b c$ & $0.198 \mathrm{~b}$ & $0.065 \mathrm{ab}$ & $2.75 \mathrm{~b}$ \\
\hline 30 & 0 & $6.8 \mathrm{~cd}$ & $7.5 \mathrm{~d}$ & $1.06 \mathrm{c}$ & $0.68 \mathrm{~d}$ & $0.14 \mathrm{c}$ & $0.09 \mathrm{~b}$ & $0.119 a b$ & $0.062 \mathrm{~cd}$ & $0.181 \mathrm{~b}$ & $0.05 b c$ & $4.87 \mathrm{a}$ \\
\hline 30 & 1 & $5.5 \mathrm{~d}$ & $8.6 \mathrm{~cd}$ & $1.13 \mathrm{~b}$ & $0.87 \mathrm{~d}$ & $0.24 a b$ & $0.32 \mathrm{a}$ & $0.099 \mathrm{~b}$ & $0.08 \mathrm{bc}$ & $0.184 \mathrm{~b}$ & $0.053 b c$ & $2.21 b c$ \\
\hline 30 & 3 & $10.3 \mathrm{~b}$ & $12.2 \mathrm{~b}$ & $1.10 \mathrm{~b}$ & $1.24 \mathrm{c}$ & $0.30 \mathrm{a}$ & $0.11 \mathrm{~b}$ & $0.112 \mathrm{ab}$ & $0.089 b c$ & $0.201 \mathrm{~b}$ & $0.061 b c$ & $4.34 \mathrm{a}$ \\
\hline
\end{tabular}

جدول F- اثر عصاره ميوه كيوى بر رشد گل جاليز.

Table 4. Effect of kiwi fruit extract on the growth of broomrape.

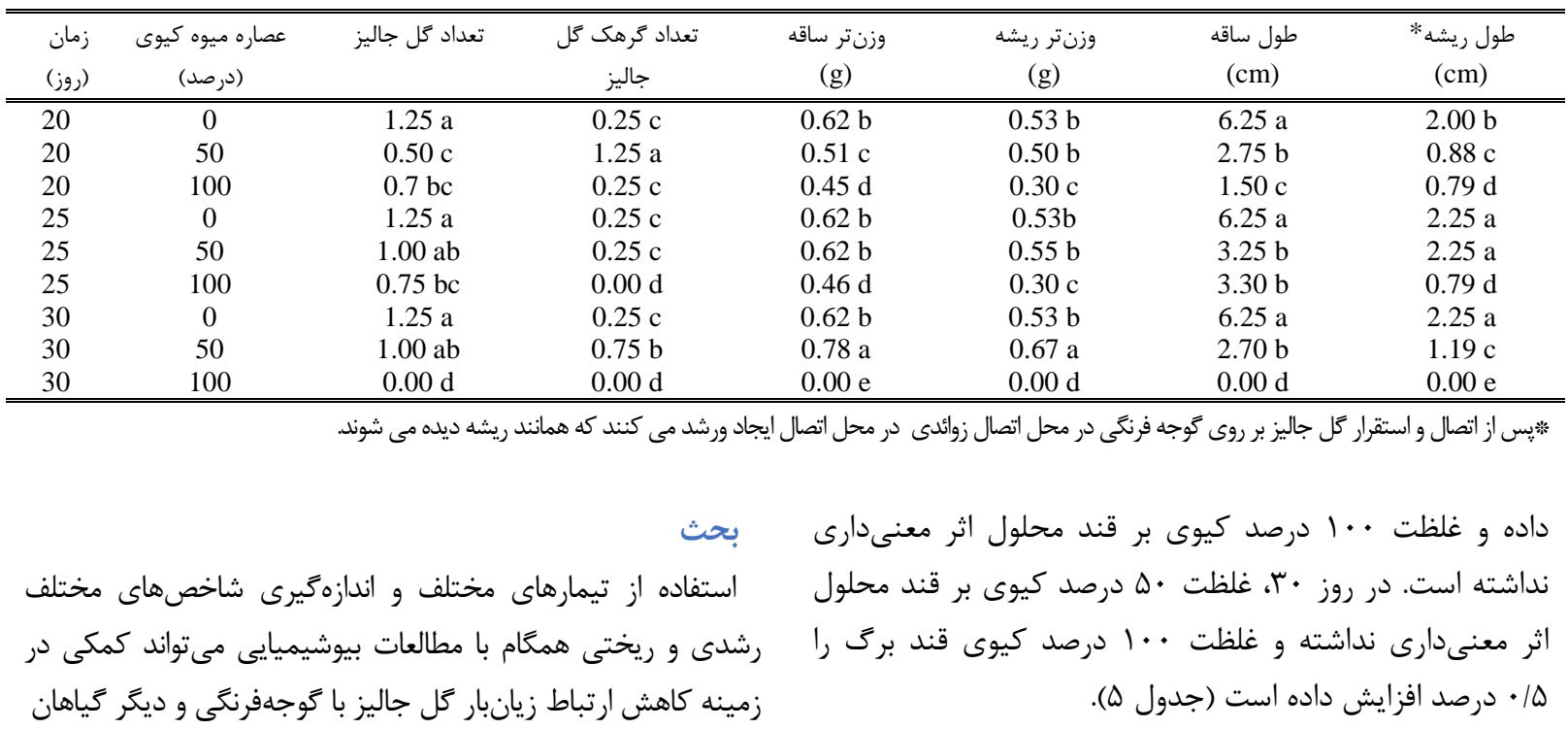


جدول ه- اثر عصاره ميوه كيوى بر سطح برى، طول ريشه، وزنتر ساقه و ريشه، وزن خشك ساقه و ريشه، رنخيزههاى فتوسنتزى و قند محلول گوجهفرنگى.

Table 5. Effect of kiwi fruit extract on the leaf area, root length, shoot fresh weight, root fresh weight, shoot dry weight and root dry weight, photosynthesis pigments and sugar content of tomato.

\begin{tabular}{|c|c|c|c|c|c|c|c|c|c|c|c|c|}
\hline زمان & عصاره ميوه & $\begin{array}{c}\text { سطرح } \\
\left(\mathrm{cm}^{2}\right)\end{array}$ & $\begin{array}{l}\text { ريشه } \\
(\mathrm{cm})\end{array}$ & وزن & وزن & وزنه خشك (g) & وزيش خشك رو) & $\begin{array}{c}a \text { كلروفيل } \\
\left(\mathrm{mg} \mathrm{g}^{-1}\right. \\
\text { FW) }\end{array}$ & 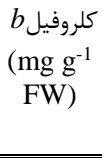 & $\begin{array}{c}\text { كلروفيل } \\
\text { كل } \\
\left(\mathrm{mg} \mathrm{g}^{-1}\right. \\
\mathrm{FW}) \\
\end{array}$ & $\begin{array}{c}\text { كاروتنوئيد } \\
\left(\mathrm{mg} \mathrm{g}^{-1}\right. \\
\text { FW) }\end{array}$ & $\begin{array}{c}\text { قند } \\
\text { قحلول } \\
\left(\mathrm{mg} \mathrm{g}^{-1}\right. \\
\text { FW) } \\
\end{array}$ \\
\hline 20 & 0 & $6.75 \mathrm{e}$ & $7.5 \mathrm{~d}$ & $1.06 \mathrm{~d}$ & $0.68 \mathrm{~d}$ & $0.13 \mathrm{c}$ & $0.09 \mathrm{~d}$ & $0.119 a$ & $0.063 \mathrm{c}$ & $0.181 \mathrm{~b}$ & $0.059 \mathrm{a}$ & $4.87 \mathrm{a}$ \\
\hline 20 & 50 & $9.75 \mathrm{~b}$ & $10.5 b c$ & $1.19 \mathrm{~d}$ & $1.53 \mathrm{c}$ & $0.17 b c$ & $0.29 b c$ & $0.078 \mathrm{~b}$ & $0.043 \mathrm{c}$ & $0.120 \mathrm{~d}$ & $0.041 \mathrm{~b}$ & $3.30 \mathrm{~b}$ \\
\hline 20 & 100 & $9.25 b c$ & $9.45 \mathrm{c}$ & $1.55 \mathrm{bc}$ & $1.92 \mathrm{c}$ & $0.20 b c$ & $0.44 \mathrm{a}$ & $0.109 a b$ & $0.101 \mathrm{~b}$ & $0.210 \mathrm{ab}$ & $0.060 \mathrm{a}$ & $1.38 \mathrm{e}$ \\
\hline 25 & 0 & $6.75 \mathrm{e}$ & $7.5 \mathrm{~d}$ & $1.06 \mathrm{~d}$ & $0.68 \mathrm{~d}$ & $0.13 \mathrm{c}$ & $0.09 \mathrm{~d}$ & $0.119 \mathrm{a}$ & $0.063 \mathrm{c}$ & $0.181 \mathrm{~b}$ & $0.059 a$ & $4.87 \mathrm{a}$ \\
\hline 25 & 50 & $7.25 \mathrm{de}$ & $9.9 \mathrm{bc}$ & $1.44 \mathrm{c}$ & $2.08 b c$ & $0.13 \mathrm{c}$ & $0.22 \mathrm{c}$ & $0.099 \mathrm{ab}$ & $0.049 \mathrm{c}$ & $0.148 \mathrm{~cd}$ & $0.043 b$ & $2.03 \mathrm{~d}$ \\
\hline 25 & 100 & $8.25 \mathrm{~cd}$ & $10.5 b c$ & $1.49 \mathrm{c}$ & $1.84 \mathrm{c}$ & $0.22 \mathrm{ab}$ & $0.30 b c$ & $0.081 \mathrm{ab}$ & $0.062 \mathrm{c}$ & $0.149 \mathrm{~cd}$ & $0.043 b$ & $1.53 \mathrm{de}$ \\
\hline 30 & 0 & $6.75 \mathrm{e}$ & $7.5 \mathrm{~d}$ & $1.06 \mathrm{~d}$ & $0.68 \mathrm{~d}$ & $0.14 \mathrm{c}$ & $0.09 \mathrm{~d}$ & $0.119 \mathrm{a}$ & $0.063 \mathrm{c}$ & $0.181 b c$ & $0.059 \mathrm{a}$ & $4.87 \mathrm{a}$ \\
\hline 30 & 50 & $9.50 b c$ & $14.2 \mathrm{a}$ & $1.78 \mathrm{~b}$ & $2.64 \mathrm{ab}$ & $0.24 a b$ & $0.41 \mathrm{ab}$ & $0.100 \mathrm{ab}$ & $0.062 \mathrm{c}$ & $0.162 \mathrm{~cd}$ & $0.054 \mathrm{ab}$ & $2.86 b c$ \\
\hline 30 & 100 & $15.7 \mathrm{a}$ & $12 \mathrm{~b}$ & $2.02 \mathrm{a}$ & $2.97 \mathrm{a}$ & $0.30 \mathrm{a}$ & $0.34 \mathrm{ab}$ & $0.109 \mathrm{ab}$ & $0.109 \mathrm{a}$ & $0.252 \mathrm{a}$ & $0.063 \mathrm{a}$ & $2.65 \mathrm{c}$ \\
\hline
\end{tabular}

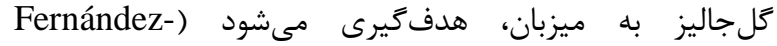
Aparicio et al., 2016; Zamanzadeh et al., 2011 روشها، بر مبناى استفاده از زنوتيبهاى مقاوم شده از طريق

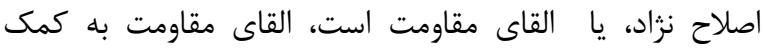

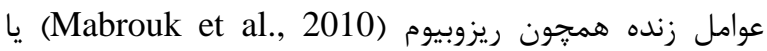

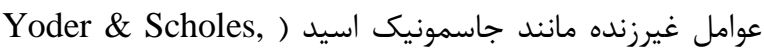

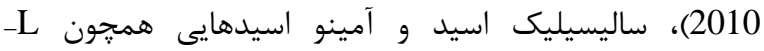
متيونين و بتاآمينوبوتيريك اسيد (Hasabi et al., 2014) صورت مى گيرد. استراترىهاى ديخرى هم براى مقابله در مراحل ديگر جرخه زندگى گل جاليز، بعد از استقرار دانهرست Fernández-Aparicio et al., ) جاليز، انديشيده شده است بتهن 2016). اكثر روشهاى فوق در ايران هم بهكار كرفته شدهاند اما هنوز روش مقابله قطعى و (Torabi \& Hadizade, 2014)

$$
\text { مؤثرى در دسترس نيست. }
$$

در راستاى دسترسى به روشهاى جديد مولكولى، در اين

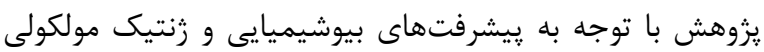

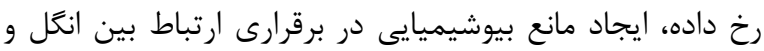

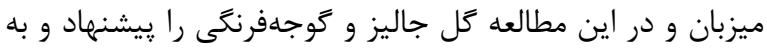

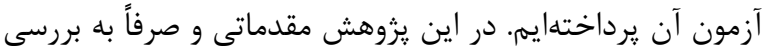

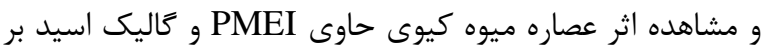

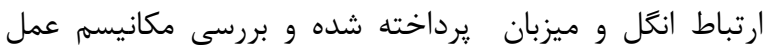
مدنظر نبوده است. در برقرارى ارتباط بين گل جاليز و گياه گوجهفرنگى، ابتدا

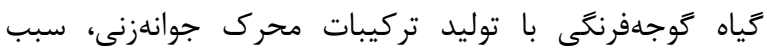
جوانهزنى بذر گل جاليز شده و ريشه پاه آن ظاهرمى شود. اين

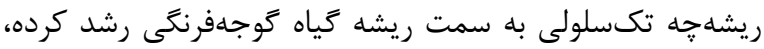
به آن رسيده و درنهايت اندامك مكنده هاستوريوم را در انتهاى

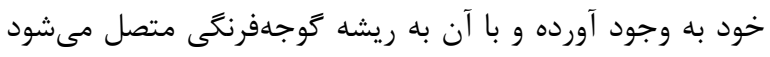

ميزبان اين گياه انگلى باشد. تحقيقات فراوانى در زمينه رشد گل جاليز در حضور ميزبان صورت گرفته است كه همگى بيانگر

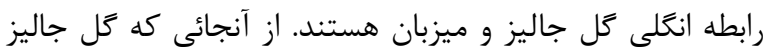
فاقد رنكَيزهاى فتوسنتزى و ريشه حقيقى است در نتيجه كاملاً

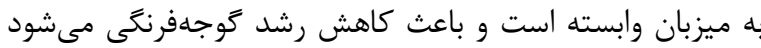
(Eizenberg et al., 2006). در يروهش حاضر هم گل جل جاليز

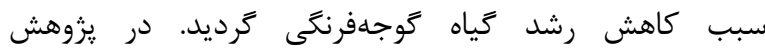

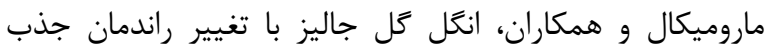
كربن از طريق كاهش در محتواى كلروفيل برگ، سرعت

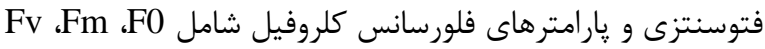
Fv / Fm بر كاهش زيستتوده گوجهفرنگى اثر داشته است كه با نتايج حاصل از يزوهش ما (Mauromicale et al., 2008) همسو است. لازمه حفظ عملكرد و كيفيت محصول زوجهفرنكى مقابله با گل جاليز است. در طى سالهاى گذشته، براى مقابله با كل جاليز، روشهاى متعددى بر مبناى تأثير بر مراحل خاصى از

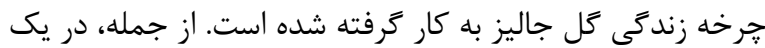
سرى از روشها، اتصال بذر جوانهزه گل جاليز به گياه ميزبان، هدفگيرى شده و بذر روئيده انگل، خنثى و غيرفعال مىشود.

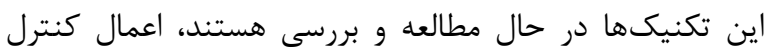
بيولوزيكى به به كمك حشرات (Aly, 2007)، قارجها (Hershenhorn et al., 2009) 2004)، انجام كنترل شيميايى، فيزيكى و كنترل كشت و زراعت، مانند استفاده از علفكشها، تيمار يا تدخين خاى با كَازهاى سمى و حرارت دهى آفتابى خاك، وجين دستى، استفاده از

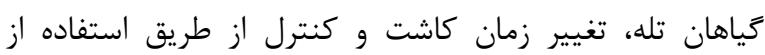
ميزبانهاى مقاوم، از جمله تكنيكها هستند كه در جهان ممانعت از رويش بذر گل جاليز و يا غير فعال كردن بذر روئيده عمل مى كنند. در ديكر استراتزىهاى كنترل، نفوذ جوانه 
استفاده از عصاره كيوى و بررسى نقش بازدارنده آن بر رابطه

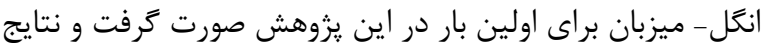
خوبى را به همراه داشته است. كاليك اسيد و عصاره ميوه كيوى علاوه بر كاهش رشد رداه

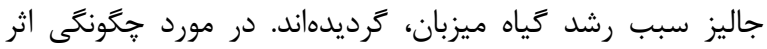

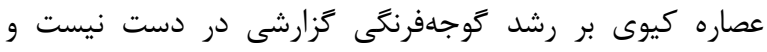

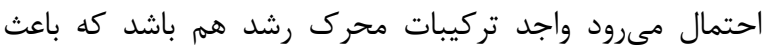
افزايش رشد كياه مىشود؛ كه نياز به بررسى و مطالعه دارد. اما در

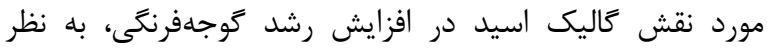

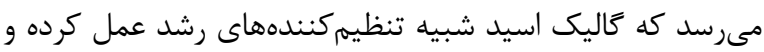
فعاليت شبه اكسينى دارد (Campobenedetto et al., 2021).

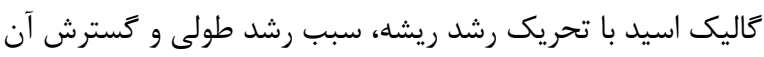

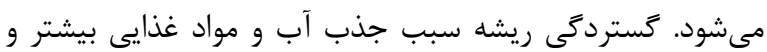

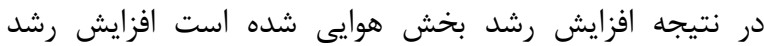

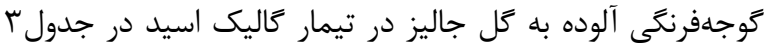
مشاهده مىشود. در يروهش بر روى برنج و كاربرد كاليك اسيد و

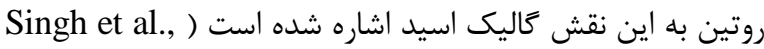

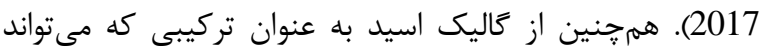

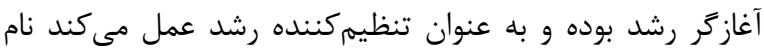
برده شده است و آن را در توسعه ريشه مؤثر مىدانند ( Negi et

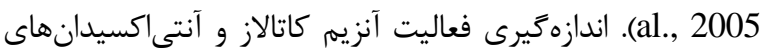

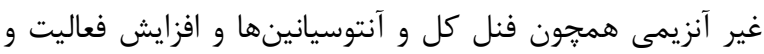
كميت آنها در كوجافرنكى تحت تأثير عصاره كيوى ( Arshi et آنتر

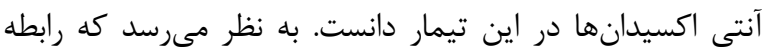

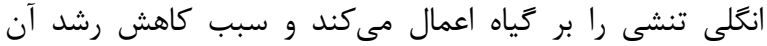

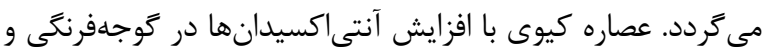

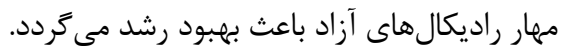
در يزوهشى ديخر به رشد برنج تحت تأثير كاليك اسيد اشاره شداء و اين افزايش رشد را به افزايش TPC (محتواى فنل كل) و TFC (محتواى فلاونوئيد كل) تحت تأثير كاليك اسيد مربوط دانسته شده آندائ كه باعث كاهش راديكال سوير اكسيد و آباكسيرنه شده است Mauromicale et al., 2008)

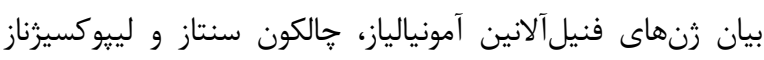

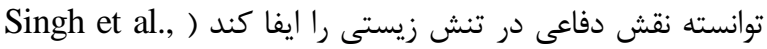

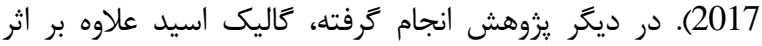

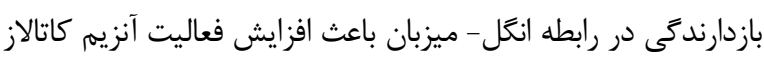

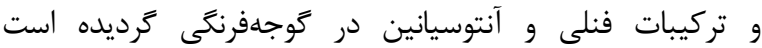

(Salimi et al., 2020)
) و با ترشح آنزيمهاى هيدرولاز، يكتيناز و (Joel et al. 2007)

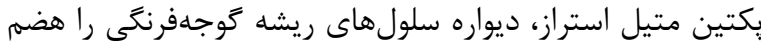

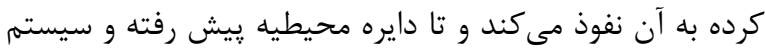

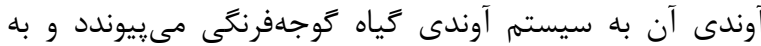
جذب آب و مواد مغذى از ريشه كَياه ميزبان مى يردازد؛ كه بسته آنها به سطح آلودگى، حساسيت ميزبان و شرايط محيطى مى تواند به ريه ميزان قابلتوجهى باعث كاهش بهرهورى و يا حتى از بين بردن مئن

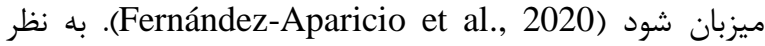
مىرسد آنزيم يكتين متيل استراز نقش مؤثرترى در فرايند نفون

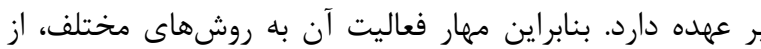

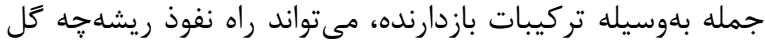

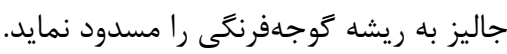

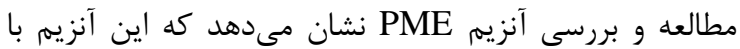

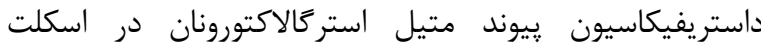

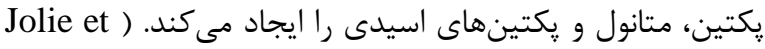
اين آنزيم بازدارندههاى متعددى دارد و يروتينين (al., 2010 PMEI

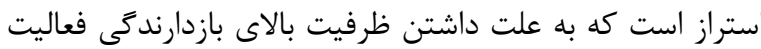

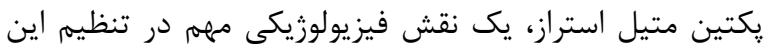
آنزيم در كياه بر عهده دارد. فرم فعال اين بازدارنده يروتئين فئينى تنهيا

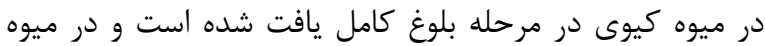

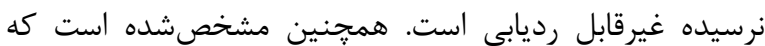
سطوح بيان نسبى زنهاى PMEI در ميوه كيوى، با افزايش رسيدكى ميوه افزايش مىيابد. تركيبات فنولى همجون تاليك

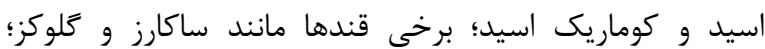
كليسرول از ديكر بازدارندههاى آنزيم گُكتين متيل استراز

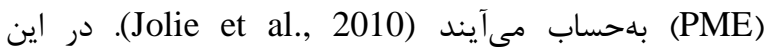

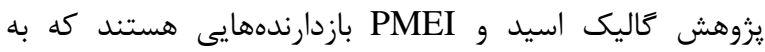

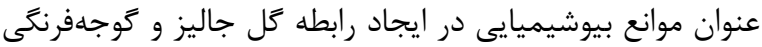
مورد آزمايش و بررسى قرار كرفتند. تأثير اين بازدارندهها بر برايز

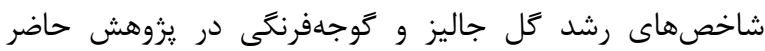

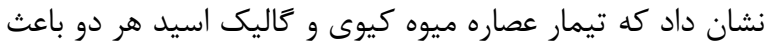
كاهش رشد گل جاليز شده و ارتفاع ساقه، طول ريشه، وزنتر

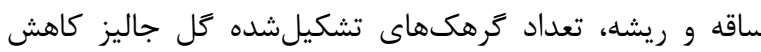
يافته است؛ بنابراين مىتوان نتيجه كرفت كه كاليك اسيد و

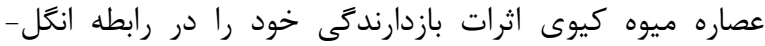

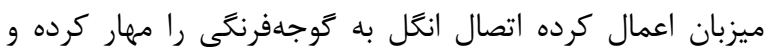
باعث كاهش رشد زل جاليز شدهاند و باعث كاهش تعداد يايههاى گل جاليز روئيده و مستقر نسبت به شاهد هم شدهاند. 


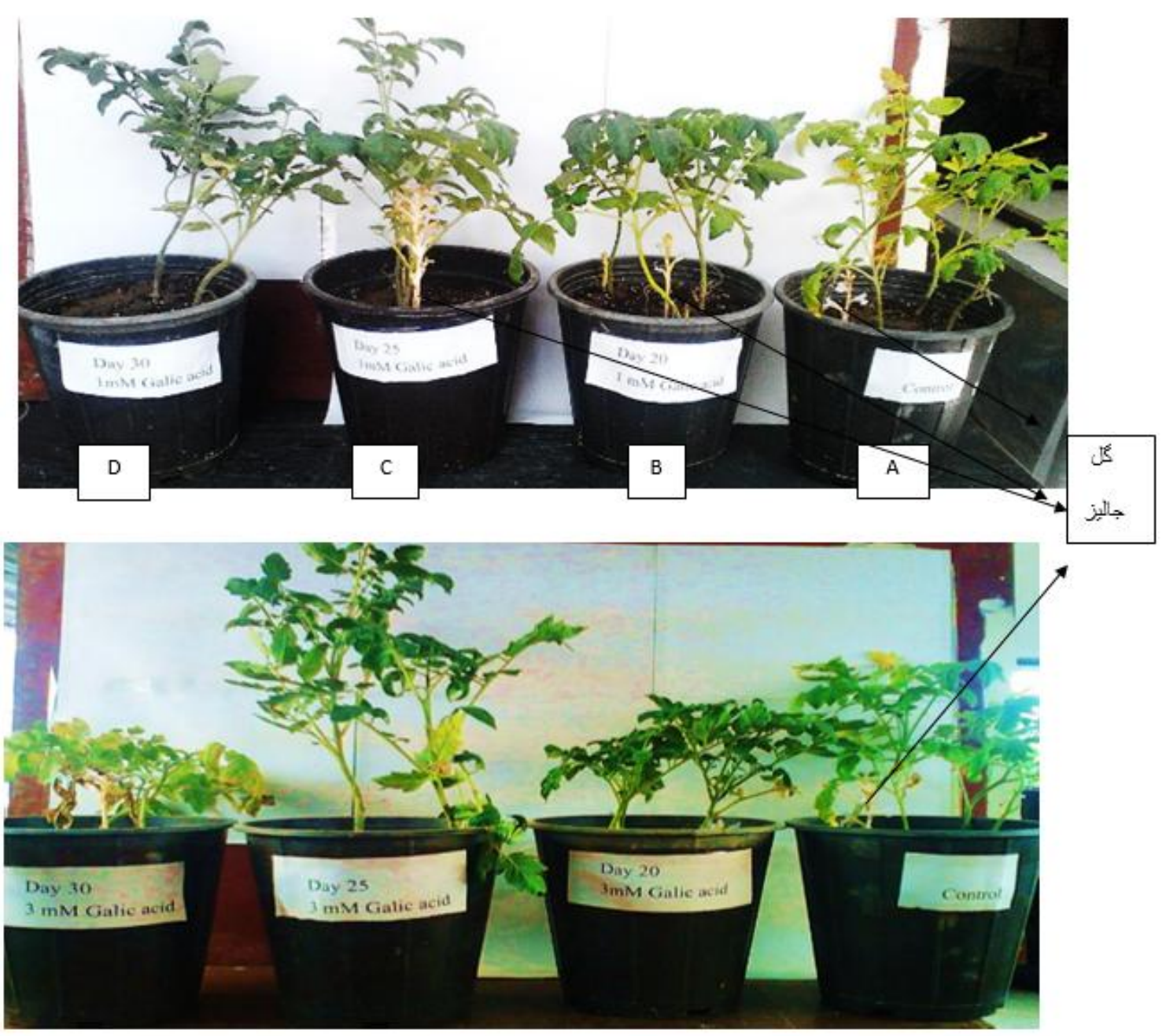

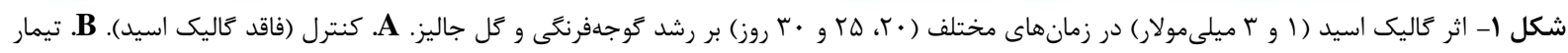

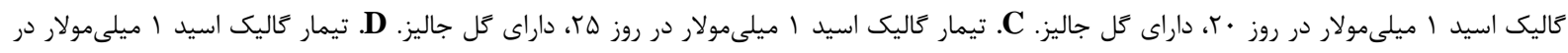

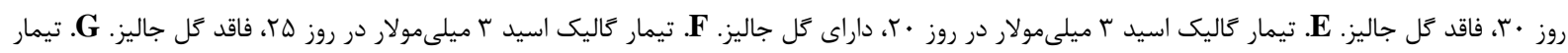

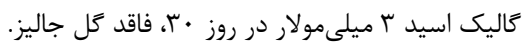

Figure 1. Effect of gallic acid (1 and $3 \mathrm{mM})$ in different times $(20,25$ and 30 days) on growth of tomato and broomrape. A. Control, gallic acid-free. B. $1 \mathrm{mM}$ gallic acid treatment on day 20, with broomrape. C. $1 \mathrm{mM}$ gallic acid treatment on day 25 , with broomrape. D. $1 \mathrm{mM}$ gallic acid treatment on day 30, no broomrape. E. $3 \mathrm{mM}$ gallic acid treatment on day 20, with broomrape. F. $3 \mathrm{mM}$ gallic acid treatment on day 25, no broomrape. G. $3 \mathrm{mM}$ gallic acid treatment on day 30 , no broomrape.

كاليك اسيد بر فاكتور WRKY كه به عنوان عامل كليدى در مسير علامتدهى جاسمونات، ساليسيليك اسيد و اتيلن اثر دارد و به نظر مىرسد از اين طريق توانسته در شرايط تنشى النى ايفاى

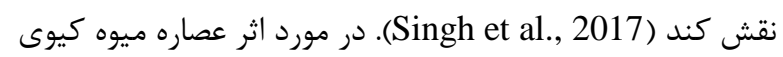

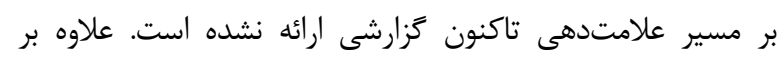

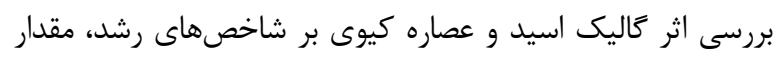

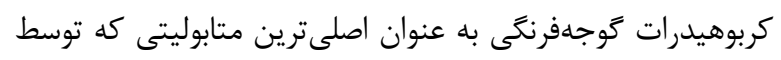
كل جاليز مصرف مىشود در كياهان تحت تيمار كاليك اسيد،

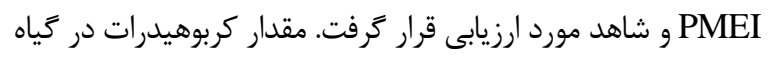

$$
\begin{aligned}
& \text { بنابراين اين تأثير را مىتوان به اثر شبه اكسينى آن در افزايش } \\
& \text { رشد توجهفرنكى افزود. }
\end{aligned}
$$

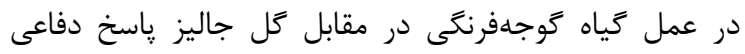

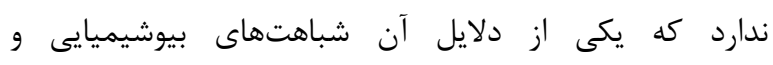

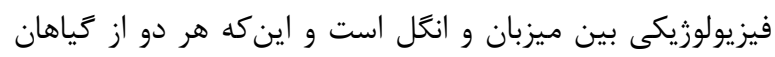

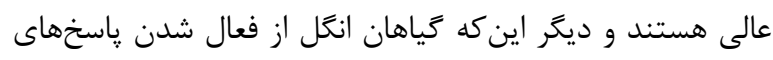

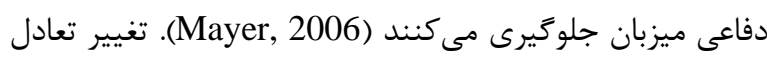

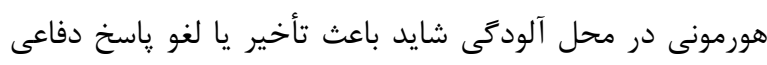

$$
\begin{aligned}
& \text { كياه مىشود (Jiang et al., 2004). }
\end{aligned}
$$




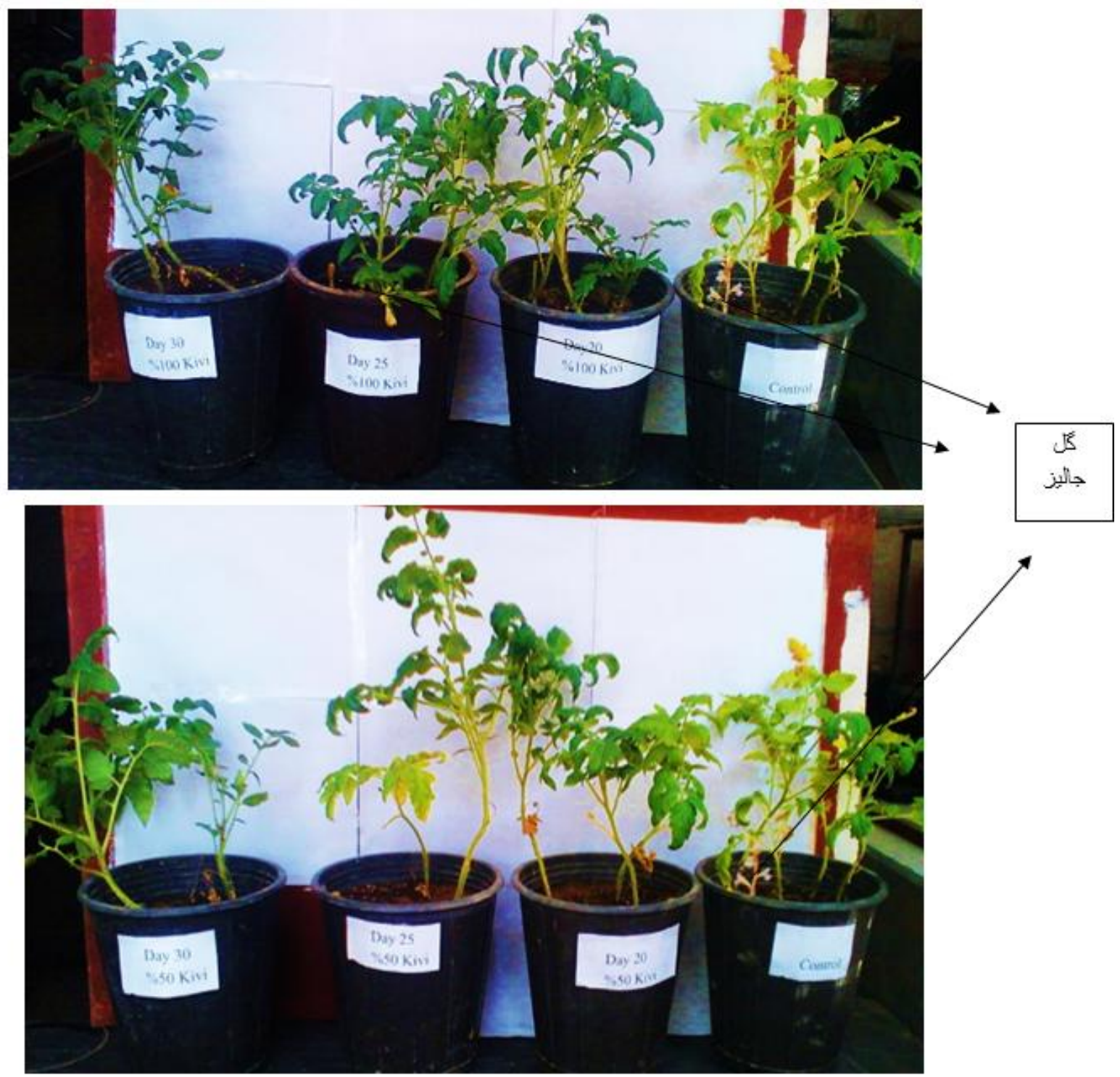

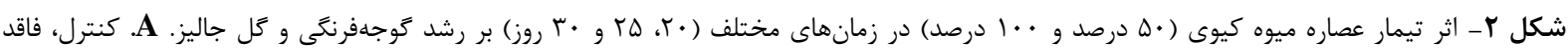

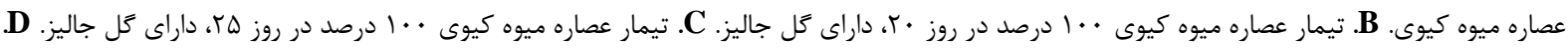

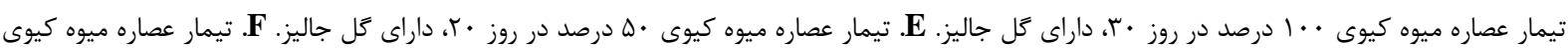

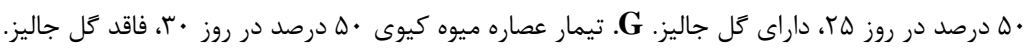

Figure 2. Effect of kiwi fruit extract (50\% and 100\%) in different times (20, 25 and 30 days) on growth of tomato and broomrape. A. Control, kiwi fruit extract free. B. Treatment of $100 \%$ kiwi fruit extract on day 20, with broomrape. C. Treatment of $100 \%$ kiwi fruit extract on day 25, with broomrape. D. Treatment of $100 \%$ kiwi fruit extract in Day 30, with broomrape. E. 50\% kiwi fruit extract treatment on day 20, with broomrape. F. 50\% kiwi fruit extract treatment on day 25 , with broomrape. G. $50 \%$ kiwi fruit extract treatment on day 30 , no broomrape.

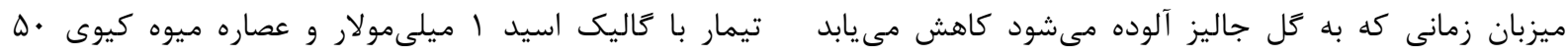

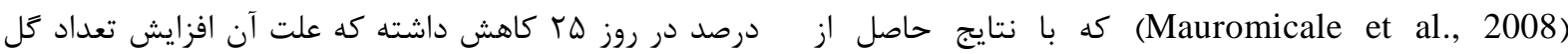

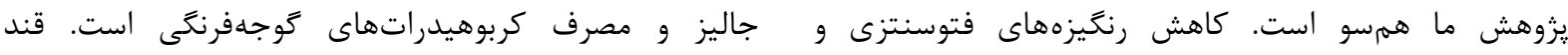

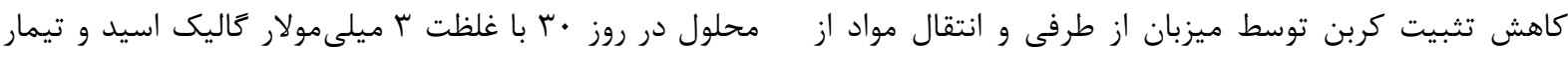

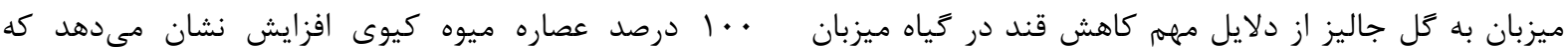

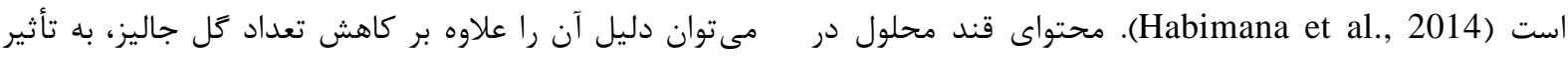




$$
\begin{aligned}
& \text { سياسخز ارى } \\
& \text { اين تحقيق در دانشعاه خوارزمى انجامشده است. نويسندكان بر }
\end{aligned}
$$

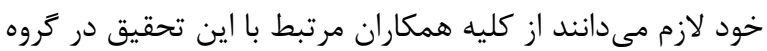

$$
\begin{aligned}
& \text { علوم گياهى دانشكده علوم زيستى سياسگز ارى نمايند. }
\end{aligned}
$$

\section{REFERENCES}

Aly, R. 2007. Conventional and biotechnological approaches for control of parasitic weeds. In Vitro Cellular \& Developmental Biology-Plant 43: 304-317.

Arshi, A., Salimi, A. \& Chavoushi, M. 2020. The effects of kiwi on physiology parameters in tomato (Lycopersicon esculentum) infected with broomrapes (Orobanche spp.). Journal of Agricultural Science and Sustainable Production. (In Press).

Berger, S., Sinha, A.K. \& Roitsch, T. 2007. Plant physiology meets phytopathology: plant primary metabolism and plant-pathogen interactions. Experimental Botany 58: 4019-4026.

Campobenedetto, C., Mannino, G., Beekwilder, J., Contartese, V., Karlova, R. \& Bertea, C. M. 2021. The application of a biostimulant based on tannins affects root architecture and improves tolerance to salinity in tomato plants. Scientific Reports 11: 1-15.

Campobenedetto, C., Mannino, G., Beekwilder, J., Contartese, V., Karlova, R. \& Bertea, C.M. 2021. The application of a biostimulant based on tannins affects root architecture and improves tolerance to salinity in tomato plants. Scientific Reports 11: 1-15.

Dadon, T., Nun, N.B. \& Mayer, A.M. 2004. A factor from Azospirillum brasilense inhibits germination and radicle growth of Orobanche aegyptiaca. Israel Journal of Plant Sciences 52: 83-86.

Eizenberg, H., Colquhoun, J.B. \& Mallory-Smith, C.A. 2006 .Imazamox application timing for small broomrape (Orobanche minor) control in red clover. Weed Science 54: 923-927.

Eizenberg, H. \& Goldwasser, Y. 2018. Control of egyptian broomrape in processing tomato: A summary of 20 years of research and successful implementation. Plant Disease 102: $1477-1488$.

Fernández-Aparicio, M., Delavault, P. \& Timko, M.P. 2020. Management of infection by parasitic weeds: A review. Plants 9: 1184-1190.

Fernández-Aparicio, M., Reboud, X.\& Gibot-Leclerc, S. 2016. Broomrape weeds. Underground mechanisms of parasitism and associated strategies for their control: a review. Frontiers in plant science 7: 5188-5196.

Gevezova, M., Dekalska, T., Stoyanov, K., Hristeva, T., Kostov, K., Batchvarova, R. \& Denev, I. 2012. Recent Advances in Broomrapes Research. BioScience and Biotechnology 1: 91-105.

Giovane, A., Laratta, B., Loiudice, R., Quagliuolo, L., Castaldo, D. \& Servillo, L. 1996. Determination of residual pectin methylesterase activity in food products. Biotechnology and Applied Biochemistry 23: 181-184.

Habimana, S., Nduwumuremyi, A. \& Chinama, R. 2014. Managementof orobanche in field crops: A review. Journal of Soil Science and Plant Nutrition 14: 43-62.

$$
\begin{aligned}
& \text { كاليك اسيد و عصاره كيوى بر رنخيزههاى فتوسنتزى، تثبيت } \\
& \text { كربن و افزايش زيست توده مربوط دانست. نوعى ارتباط مثبت } \\
& \text { بين محتواى كلروفيل و ميزان فتوسنتز زياه وجود دارد، } \\
& \text { بهورى كه با افزايش كلروفيل، فتوسنتز نيز افزايش مىيابد } \\
& \text { كه منجر به افزايش رشد مىشود در اين تحقيق افزايش } \\
& \text { كلروفيل bا و كلروفيل كل در تيمار با عصاره ميوه كيوى } \\
& \text { مشاهدهده است. هرجند كه زاليك اسيد بر رنتيزه هاى } \\
& \text { فتوسنتزى گوجهفرنكى اثر معنى دارى نداشته است. در هر هر }
\end{aligned}
$$

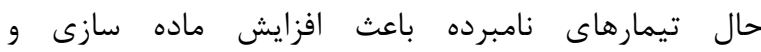

$$
\begin{aligned}
& \text { كربوهيدرات و به دنبال آن باعث افزايش وزن خشك ساقه و }
\end{aligned}
$$

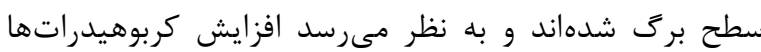

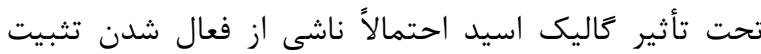

$$
\begin{aligned}
& \text { كربن باشد. } \\
& \text { در بيان اهميت نقش كاليك اسيد، مىتوان به نقش آن در }
\end{aligned}
$$

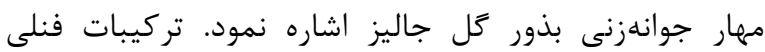

$$
\begin{aligned}
& \text { باعث اختلال شديد فيزيولوزيكى در جوانه زدن گل جل جاليز شده } \\
& \text { است. جوانهزنى دانههاى جاليز توسط GR24 آنالوى استريكول } \\
& \text { القا مىشود كه تركيبات فنلى با مهار تركيب نامبرده از }
\end{aligned}
$$

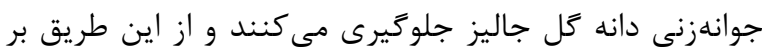

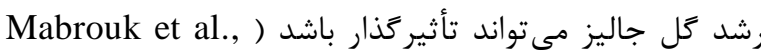

$$
\text { نتيجه تيرى }
$$

بررسى نتايج مختلف اين يزوهش نشان داد كاليك اسيد و عصاره كيوى در ايفاى نقش بازدارندگى آنزيم يكتين متيل استراز

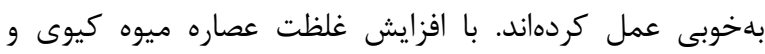

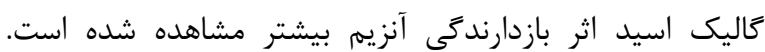

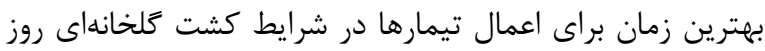

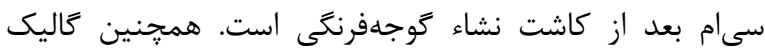

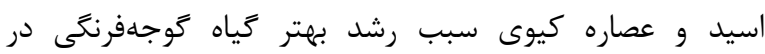

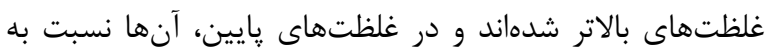
تيمار شاهد رشد كمترى داشتهاند؛ به عبارت ديگر اين تركيبات،

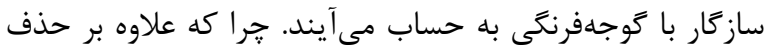
اثر گل جاليز، رشد آنها را نيز تحريك نموده است. ضمن آنكه در مهار جوانهزنى بذرهاى گل جاليز هم مؤثر بودهاند؛ بنابراين

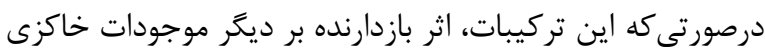
نداشته و بر طعم، كيفيت و ماندگارى ميوه آن اثر سويى نداشته مئه

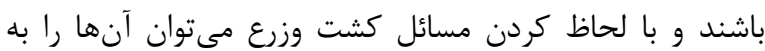

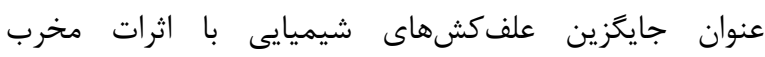
زيستمحيطى در نظرگرفت. 
Hershenhorn, J., Eizenberg, H., Dor, E., Kapulnik, Y. \& Goldwasser, Y. 2009. Phelipanche aegyptiaca management in tomato. Weed Research 49: 34-47.

Jiang, F., Jeschke, W.D. \& Hartung, W. 2004. Abscisic acid (ABA) flows from Hordeum vulgare to the hemiparasite Rhinanthus minor and the influence of infection on host and parasite abscisic acid relations. Experimental Botany 55: 2323-2329.

Jolie, R.P., Duvetter, T., Houben, K., Vandevenne, E., Van Loey, A.M., Declerck, P.J., Hendrickx, M.E. \& Gils, A. 2010. Plant pectin methylesterase and its inhibitor from kiwi fruit: Interaction analysis by surface plasmon resonance. Food Chemistry 121: 207-214.

Jolie, R.P., Duvetter, T., Houben, K., Clynen, E., Sila, D.N., Van Loey, A.M. \& Hendrickx, M.E. 2009. Carrot pectin methylesterase and its inhibitor from kiwi fruit: Study of activity, stability and inhibition. Innovative Food Science \& Emerging Technologies 10: 601-609.

Joel, D.M., Hershenhorn, J., Eizenberg, H., Aly, R., Ejeta, G., Rich, P.J. \& Rubiales, D. 2007. Biology and management of weedy root parasites. Horticultural Reviews Westport Then New York, 267 pp.

Hasabi, V., Askari, H., Alavi, S. M. \& Zamanizadeh, H. 2014. Effect of amino acid application on induced resistance against Citrus canker disease in lime plants. Plant Protection Research 54, 144-149.

Karampour, F. 2010. Familiarity with the parasite of comfrey and its management methods. Agricultural Research, Education and Extension Organization. Boshehr, 40 pp. (In Persian).

Kochert, G. 1978. Carbohydrate determination by the phenol-sulfuric acid method. Handbook of Phycological Methods: Physiological and Biochemical Methods 95: 57-97.

Lichtenthaler, H.K. 1987. Chlorophylls and carotenoids: pigments of photosynthetic biomembranes. Methods in Enzymology 148: 350-382.

Mabrouk, Y., Mejri, S., Hemissi, I., Simier, P., Delavault, P., Saidi, M. \& Belhadj, O. 2010. Bioprotection mechanisms of pea plant by Rhizobium leguminosarum against Orobanche crenata. African Journal of Microbiology Research 4: 2570-2575.
Mabrouk, Y., Simier, P., Arfaoui, A., Sifi, B., Delavault, P., Zourgui, L. \& Belhadj, O. 2007. Induction of phenolic compounds in pea (Pisum sativum L.) inoculated by Rhizobium leguminosarum and infected with Orobanche crenata. Phytopatholog 155: 728-734.

Mauromicale, G., Monaco, A.L. \& Longo, A.M. 2008. Effect of branched broomrape (Orobanche ramosa) infection on the growth and photosynthesis of tomato. Weed Science 56: 574-581.

Mayer, A. 2006. Pathogenesis by fungi and by parasitic plants: similarities and differences. Phytoparasitica 34: 3-16.

Negi, A.S., Darokar, M.P., Chattopadhyay, S.K., Garg, A., Bhattacharya, A.K., Srivastava, V. \& Khanuja, S.P. 2005. Synthesis of a novel plant growth promoter from gallic acid. Bioorganic \& Medicinal Chemistry Letters 15: 1243-1247.

Salimi, A., Arshi A. \& Chavoushi, M. 2020. The effects of Gallic acid on broomrape and antioxidant enzyme activity in tomato (Lycopersicum esculentum). Journal of Plant Process and Function 10: 147-159.

Sasikumar, K., Vijayalakshmi, C. \& Parthiban, K. 2006. Allelopathic effects of four Eucalyptus species on redgram (Cajanus cajan L.). Tropical Agriculture 39: 134-138.

Singh, A., Gupta, R. \& Pandey, R. 2017. Exogenous application of rutin and gallic acid regulate antioxidants and alleviate reactive oxygen generation in Oryza sativa L. Physiology and Molecular Biology of Plants 23: 301-309.

Torabi, S.H \& Hadizadeh M.H. 2014. Challenges, achievements and prospects of research on broomrape (Orobanche spp.) in Iran and in the world. Weed Ecology 1: 99-119. (In Persian).

Zamanzadeh, E., Nabavi Kalat, S.M. \& Norouzzadeh, S. 2011 Efficacy of sulfosulforon (Apyrus) and metham sodium (Vapam) herbicides on control of broomrape (Orobanche aeygptiaca) in tomato fields. Journal of Crop Weed Ecophysiolgy 5: 67-82. (In Persian).

Yoder, J.I. \& Scholes, J.D. 2010. Host plant resistance to parasitic weeds; recent progress and bottlenecks. Current Opinion in Plant Biology 13: 478-484.

How to cite this article:

Salimi, A., Arshi, A. \& Chavoushi, M. 2021. The effects of kiwi fruit extract and gallic acid on symbiotic relationship between broomrape and tomato. Nova Biologica Reperta 8: 220-232. (In Persian).

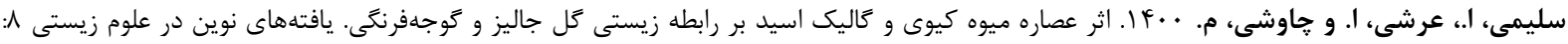

